\title{
Potential COVID-19 therapies from computational repurposing of drugs and natural products against the SARS-CoV-2 helicase
}

Sakshi Piplani ${ }^{\mathrm{a}, \mathrm{b}}$, Puneet Singh ${ }^{\mathrm{b}}$, David A. Winkler ${ }^{\mathrm{c}, \mathrm{d}, \mathrm{e}}$, Nikolai Petrovsky $^{\mathrm{a}, \mathrm{b},{ }^{*}}$

a. College of Medicine and Public Health, Flinders University, Bedford Park 5046, Australia

b. Vaxine Pty Ltd, 11 Walkley Avenue, Warradale 5046, Australia

c. Department of Biochemistry and Chemistry, La Trobe Institute for Molecular Science, La Trobe University, Melbourne, Victoria, 3086, Australia

d. Monash Institute of Pharmaceutical Sciences, Monash University, Parkville 3052, Australia

e. School of Pharmacy, University of Nottingham, Nottingham NG7 2RD. UK.

* Corresponding author: nikolai.petrovsky@flinders.edu.au

Repurposing of existing drugs is a rapid way to find potential new treatments for SARS-CoV-2. Here we applied a virtual screening approach using Autodock Vina and molecular dynamic simulation in tandem to screen and calculate binding energies of repurposed drugs against the SARS-CoV-2 helicase protein (non-structural protein nsp13). Amongst the top hits from our study were antivirals, antihistamines, and antipsychotics plus a range of other drugs. Approximately $30 \%$ of our top 87 hits had published evidence indicating in vivo or in vitro SARS-CoV-2 activity. Top hits not previously reported to have SARS-CoV-2 activity included the antiviral agents, cabotegravir and RSV-604, the NK1 antagonist, aprepitant, the trypanocidal drug, aminoquinuride, the analgesic antrafenine, the anticancer intercalator, epirubicin, the antihistamine, fexofenadine, and the anticoagulant, dicoumarol. These hits from our in silico SARS-CoV-2 helicase screen warrant further testing as potential COVID-19 treatments 


\section{Introduction}

The global COVID-19 pandemic continues to wreak economic and social havoc globally, with at least 330 million infections and 5.6 million deaths globally (January 2022). Effective vaccines and drug therapies are essential to bringing the pandemic to an end. This global challenge has seen an unprecedented and intense focus on coronavirus research, resulting in the development of vaccines in impressively short times. Similarly, empirical and limited rational selection of drugs such as remdesivir and dexamethasone provided early drug treatments that limited morbidity and mortality. However, more effective drugs are still required to treat COVID-19 and other coronavirus diseases, such as SARS and MERS, as well as new viruses that may emerge in the future.

Structural biologists have successfully characterized SARS-CoV-2 proteins that represent viable drug targets for structure-based computational design of new drugs, and for rapid repurposing of existing drugs for treatment of COVID-19. There has been extensive research into drugs that might interfere in the SARS-CoV2 spike protein's interaction with its cognate human receptor, angiotensin-converting enzyme 2 (ACE2). Other heavily studied targets are the viral $3 \mathrm{CL}$ main protease ( $\left.\mathrm{M}^{\text {pro }}, \mathrm{nsp5}\right)$, $\mathrm{PL}$ protease ( $\left.\mathrm{PL}^{\text {pro }}, \mathrm{nsp} 3\right)$, and RNA-dependent RNA polymerase (RdRp, major protein nsp12) ${ }^{1-7}$. However, less attention has been paid to other potential target proteins such as the SARS-CoV-2 helicase, the focus of the current study.

Time is critical when developing vaccines or drug treatments; new drugs typically take many years to reach the clinic. Repurposing existing drugs, clinical trials candidates, and approved natural products, that have been in man and whose toxicity, pharmacokinetics, and metabolism is already well understood, is a rational and rapid way to find effective therapies during a pandemic ${ }^{8}$. Repurposing can be done by high throughput in vitro assays, in vivo studies in animals, and computational drug design methods. Several teams have undertaken wet-lab screening of existing drugs against viral targets or viral assays, but none have achieved sufficient high throughput to allow $>10,000$ candidates to be assessed. Computational screening can be performed easily on large numbers of molecules, with relative binding affinities allowing ranking of the candidates for focused in vitro and in vivo testing followed by human antiviral trials, with minimal delay ${ }^{9,10}$.

The SARS-CoV-2 helicase (non-structural protein nsp13) has been less studied but has considerable potential for the discovery of drugs against SARS-CoV-2. Of the 16 known CoV nsp proteins, the helicase is essential for viral replication and, not surprisingly, it has the highest sequence conservation across the CoV family. ${ }^{11}$ As such, this vital enzyme represents a promising target for anti-CoV drug development as drugs targeting it have the potential to be active against all SARS-COV-2 strains. ${ }^{12}$

The helicase contains 601 amino acids and is part of the superfamily $1 B$ highly conserved within all coronaviruses. Helicases can have either 3'-5' (SF1A subfamily) or 5'-3'(SF1B subfamily) translocation polarity, defined as the direction (characterized as $5^{\prime} \rightarrow 3^{\prime}$ or $3^{\prime} \rightarrow 5^{\prime}$ ) of helicase movement on the DNA/RNA single-strand along which it is moving ${ }^{13-17}$. The SARS-CoV-2 helicase is a critical enzyme for viral replication as it initiates the first step of the RNA cap synthesis that is essential to protect the virus from innate immune attack, to stabilize it, and ensure its translation. We previously developed an in silico screening protocol that was used to identify drug repurposing candidates for SARS-CoV- $2 \mathrm{M}^{\text {pro }}$ and RdRp ${ }^{5-7}$. The utility of this approach was established by the large numbers of predicted candidates that had experimentally validated activity against SARS-CoV-2 and/or the specific target proteins.

Here we describe a comprehensive, combined molecular docking and molecular dynamics (MD) study of registered drugs, drug candidates, and approved natural products against the SARS-CoV- 2 helicase. We 
identify the most promising drug candidates for repurposing and validate many of the computational predictions using experimental data from the scientific literature.

\section{Results}

The helicase is 603 long amino acid protein and has a shape of a triangular pyramid that is divided into five sections, a zinc-binding domain (ZBD) which is attached to two Rec-A domains (Rec1A and Rec2A) and a Rec1B domain via a stalk domain (Figure 1).

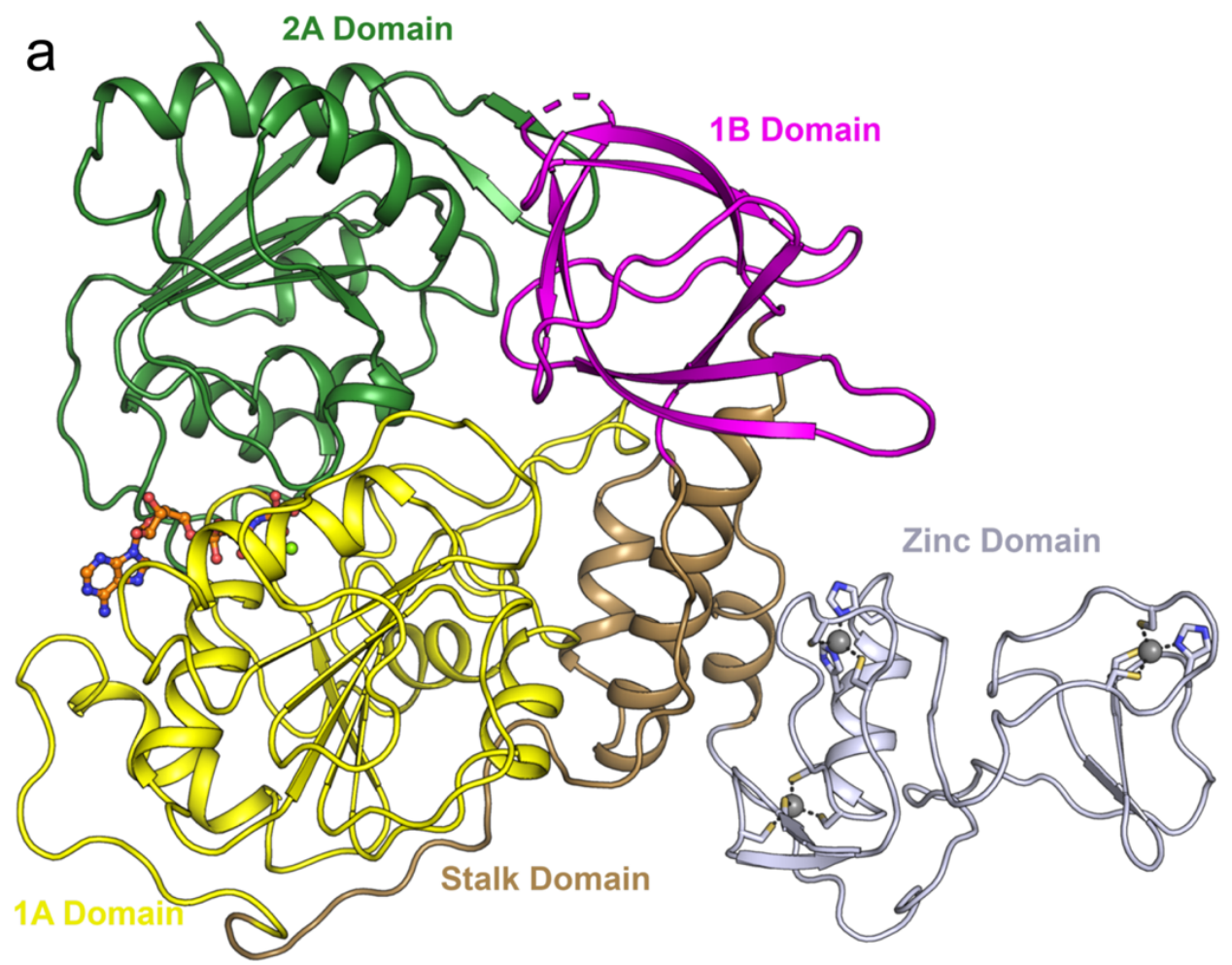

Figure 1. Domain structure of SARS-CoV-2 helicase. Used with permission from Newman et al. ${ }^{18}$

The hydrolytic activity is attributed to six key residues (Lys288, Ser289, Asp374, Glu375, Gln404, Arg567 found within the cleft between the $1 \mathrm{~A}$ and $2 \mathrm{~A}$ domains at the base. These residues are located at the active site of SARS-CoV-2 helicase enzyme. (Figure 2). The binding pocket of helicase has a volume of $325 \AA^{3}$ and an area of $420 \AA^{2}$.
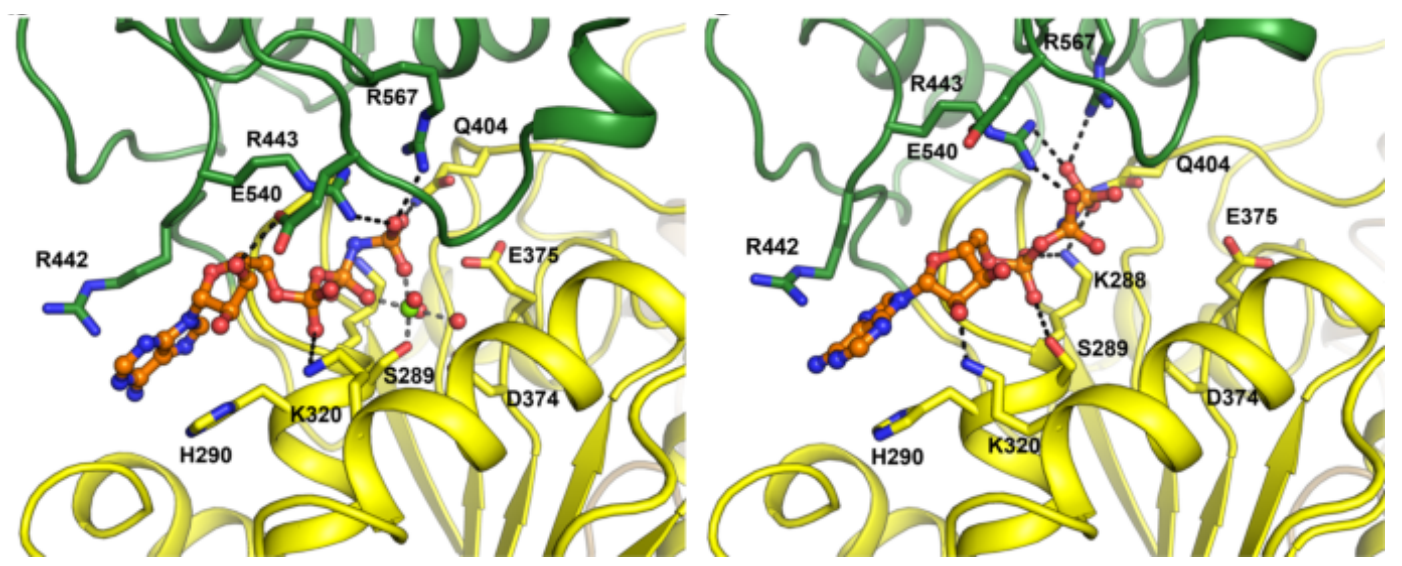

Figure 2. Key active site residues for helicase bound to the AMP-PNP Mg2+ complex (left) and the AMP-PNP complex (right). Used with permission from Newman et al. ${ }^{18}$ 
The workflow for calculating the relative binding affinities of drugs for the helicase binding pocket is summarized in Supplementary Figure S1. Autodock Vina docking followed by MD simulation of the top candidates provides improved predictions of relative binding affinities compared to docking alone. For example, significant improvement in protein-ligand docking results was shown by subsequent highthroughput MD simulations ${ }^{19}$.

The MMPBSA and thermodynamic scores for the top 87 hits in our screen correlated strongly $\left(r^{2}=0.85\right)$. Given that many of the top-ranked molecules are conformationally flexible, binding energy penalties due to ligand entropy are likely to be significant. A substantial correlation was found between the Vina scores and the binding energies from MMPBSA and the thermodynamic cycle, important because of the different ways these algorithms treat ligand entropy ${ }^{20}$.

The twenty molecules with the best helicase binding affinity are summarized in Table 1 . The compounds can be broadly characterized as containing one or more hydrophobic aromatic moieties linked to another polycyclic moiety containing hydrogen bond donors or acceptors. The top-ranked molecules come from diverse drug classes, with antiviral agents making up $25 \%$ of the hits and antihistamines and antipsychotics also being well represented.

Table 1. Binding energies of top 20 hits (ranked by MMPBSA score) against SARS-CoV-2 helicase.

\begin{tabular}{|c|c|c|c|c|}
\hline $\begin{array}{l}\text { Database } \\
\text { ID }\end{array}$ & Drug Name & Structure & 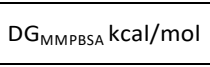 & $\begin{array}{r}\mathrm{DG}_{\text {thermo }} \\
\mathrm{kcal} / \mathrm{mol}\end{array}$ \\
\hline DB08930 & $\begin{array}{c}\text { Dolutegravir } \\
\text { (antiretroviral) }\end{array}$ & & -42.2 & -45.9 \\
\hline DB04703 & $\begin{array}{l}\text { Hesperidin } \\
\text { (citrus flavanone } \\
\text { glycoside) }\end{array}$ & & -41.2 & -39.6 \\
\hline DB11751 & $\begin{array}{c}\text { Cabotegravir } \\
\text { (antiviral integrase } \\
\text { inhibitor) }\end{array}$ & & -40.8 & -42.3 \\
\hline DB00872 & $\begin{array}{l}\text { Conivaptan } \\
\text { (vasopressin } \\
\text { inhibitor) }\end{array}$ & & -40.2 & -39.7 \\
\hline DB00673 & $\begin{array}{l}\text { Aprepitant (NK1 } \\
\text { antagonist) }\end{array}$ & & -40.1 & -45.6 \\
\hline DB11799 & $\begin{array}{l}\text { Bictegravir (antiviral } \\
\text { integrase inhibitor) }\end{array}$ & & -39.8 & -41.2 \\
\hline DB09238 & $\begin{array}{l}\text { Manidipine* (Ca } \\
\text { channel blocker, } \\
\text { anti-hypertensive) }\end{array}$ & & -39.8 & -41.3 \\
\hline DB00932 & $\begin{array}{l}\text { Tipranavir (antiviral } \\
\text { protease inhibitor) }\end{array}$ & & -39.7 & -42.6 \\
\hline DB04452 & $\begin{array}{l}\text { Aminoquinuride } \\
\text { (trypanocidal agent) }\end{array}$ & & -39.6 & -41.9 \\
\hline DB01419 & $\begin{array}{l}\text { Antrafenine } \\
\text { (analgesic anti- } \\
\text { inflammatory) }\end{array}$ & & -39.1 & -36.5 \\
\hline
\end{tabular}




\begin{tabular}{|c|c|c|c|c|}
\hline $\begin{array}{c}\text { Database } \\
\text { ID }\end{array}$ & Drug Name & Structure & $\mathrm{DG}_{\text {MMPBSA}} \mathrm{kcal} / \mathrm{mol}$ & $\begin{array}{l}\mathrm{DG}_{\text {thermo }} \\
\mathrm{kcal} / \mathrm{mol}\end{array}$ \\
\hline DB15197 & RSV-604 (antiviral) & & -38.8 & -36.2 \\
\hline DB004445 & $\begin{array}{c}\text { Epirubicin } \\
\text { (anticancer } \\
\text { intercalator) }\end{array}$ & & -38.7 & -35.6 \\
\hline DB01100 & $\begin{array}{c}\text { Pimozide } \\
\text { (antipsychotic) }\end{array}$ & & -38.4 & -35.4 \\
\hline DB01698 & $\begin{array}{l}\text { Rutin (flavonol } \\
\text { glycoside) }\end{array}$ & & -38.3 & -40.4 \\
\hline DB00266 & $\begin{array}{c}\text { Dicoumarol } \\
\text { (anticoagulant) }\end{array}$ & & -37.6 & -38.4 \\
\hline DB04842 & $\begin{array}{l}\text { Fluspirilene } \\
\text { (antipsychotic) }\end{array}$ & & -36.8 & -38.4 \\
\hline DB03044 & $\begin{array}{l}\text { Doramapimod (p38 } \\
\text { MAP kinase inhibitor) }\end{array}$ & & -36.2 & -39.5 \\
\hline DB00950 & $\begin{array}{l}\text { Fexofenadine } \\
\text { (antihistamine) }\end{array}$ & & -35.5 & -37.7 \\
\hline DB00637 & $\begin{array}{c}\text { Astemizole } \\
\text { (antihistamine) }\end{array}$ & & -35.4 & -38.7 \\
\hline DB01100 & $\begin{array}{c}\text { Sertindole } \\
\text { (antipsychotic) }\end{array}$ & & -34.6 & -36.8 \\
\hline
\end{tabular}

The remaining high binding hits included drugs and natural products used to treat a diverse range of afflictions including cancers, infections, coagulation disorders, and hypertension. Several of the top hits from our screen had experimental their SARS-CoV-2 activity determined, as do $30 \%$ of the 87 shortlisted compounds from our docking studies (Supplementary Table S1)

The calculated binding energies of the top-scoring antiviral drugs, dolutegravir, cabotegravir, bictegravir, tipranavir and RSV-604 are similar (in the range of -38.8 to $-42.2 \mathrm{kcal} / \mathrm{mol}$ by MMPBSA and -36.2 to -45.9 $\mathrm{kcal} / \mathrm{mol}$ by thermodynamic cycle). Some of the highest-ranked antiviral agents had also been identified as good binders in other in silico docking studies, providing a degree of validation that our computational 
methods are appropriate and are yielding similar results to the other published studies for these antiviral drugs.

Although the main aim of this study was to show that our computational methods are useful for rapidly identifying repurposed drugs likely to exhibit SARS-CoV-2 activities, we have also analyzed the binding of key repurposed drugs (Table 1) to the helicase active site. Figures 3-6 show LigPlot diagrams of the main interactions between four of the drugs and the binding site. They elucidate how the drugs bind to the active site of the helicase enzyme. Supplementary Figure $\$ 2$ shows a superimposition of the drugs with the most favourable binding energies in the active site of the helicase.

For hesperidin (Figure 3) four of the five rings are buried deep in the binding pocket, with the hydrophilic terminal sugar ring being exposed to the solvent. There are networks of hydrogens bond between the active site residues and the donor and acceptor groups on most repurposed drugs, especially for aminoquinuride and rutin.

Supplementary Table S2 lists the key interactions between the top screening hits and the active site of the helicase. The 6 residues in helicase binding pocket Lys288, Ser289, Asp374, Glu375, Gln404, Arg567 are crucial for ATP hydrolysis and all screened drugs interacted strongly with these residues. These molecularlevel interactions involved in binding the drugs at ATP binding site of the SARS-Cov- 2 helicase enzyme were investigated to decipher the key chemical forces crucial for intermolecular binding and stability of complexes. Cabetogravir, dicoumarol, fexofenadine, epirubicin, antrafenine, aminoquinuride, aprepitant, RSV-604 all formed strong hydrogen bonds with residues in the ATP-binding site at Rec1A domain. Aprepitant also formed $\pi$-stacking (Try541) and $\pi$-cation (Lys320) interactions with nsp-13. Antrafenine and aprepitant form halogen bonds with Ile399 and Asp374 respectively.
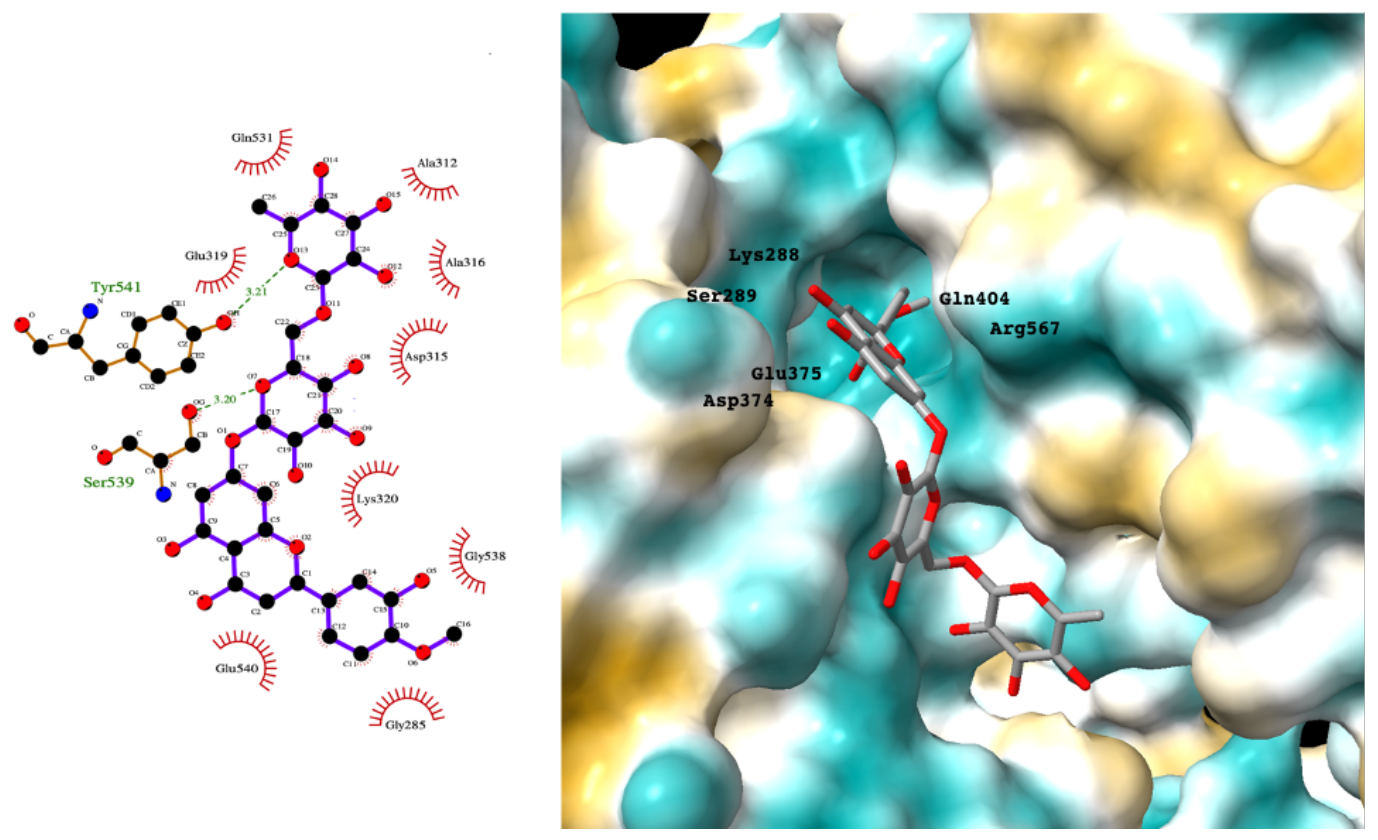

Figure 3. LigPlot (left) shows the key active site residues interacting with hesperidin. The molecular model (right) shows the binding of hesperidin to the active site cleft of the helicase. The molecular surface denotes hydrophobicity of the pockets (blue hydrophilic, yellow/brown hydrophobic). Positions of key binding site residues are labelled. 
For the antiviral integrase drug, carbogravir (Figure 4), the tricyclic ring is buried deep within the active site of the helicase. Again, the abundant hydrogen bond donors and acceptors on the polycyclic moiety form hydrogen bonds with the binding site residues of the helicase.
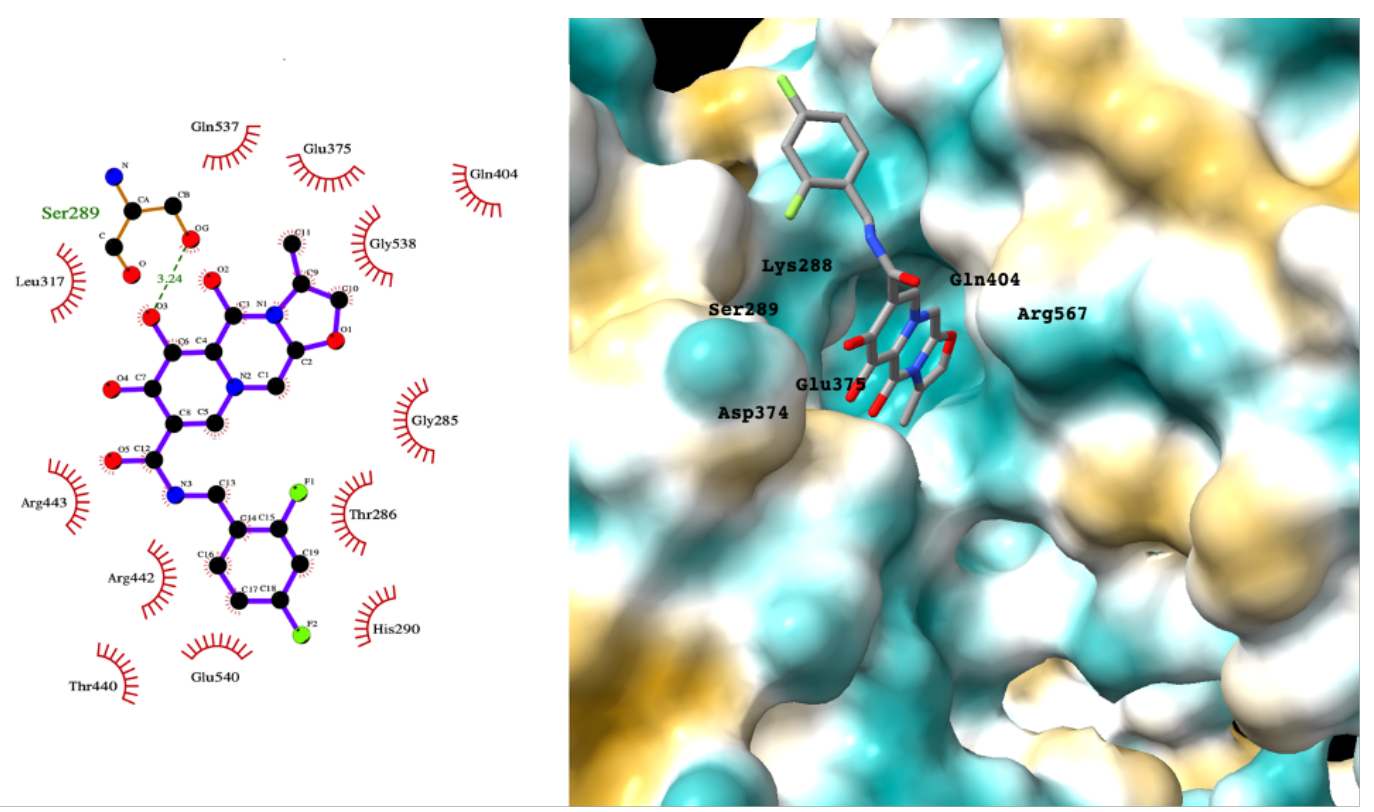

Figure 4. LigPlot (left) shows the key active site residues interacting with cabotegravir. The molecular model (right) shows the binding of cabotegravir to the active site cleft of the helicase. The tricyclic ring moiety is deeply embedded in a hydrophilic pocket. The molecular surface denotes hydrophobicity of the pockets (blue hydrophilic, yellow/brown hydrophobic). Positions of key binding site residues are labelled.

The vasopressin inhibitor, canivaptan (Figure 5), buries its hydrophilic nitrogen-rich heterocyclic rings deep within the binding cleft, forming a range of hydrogen bonds with active site residues.
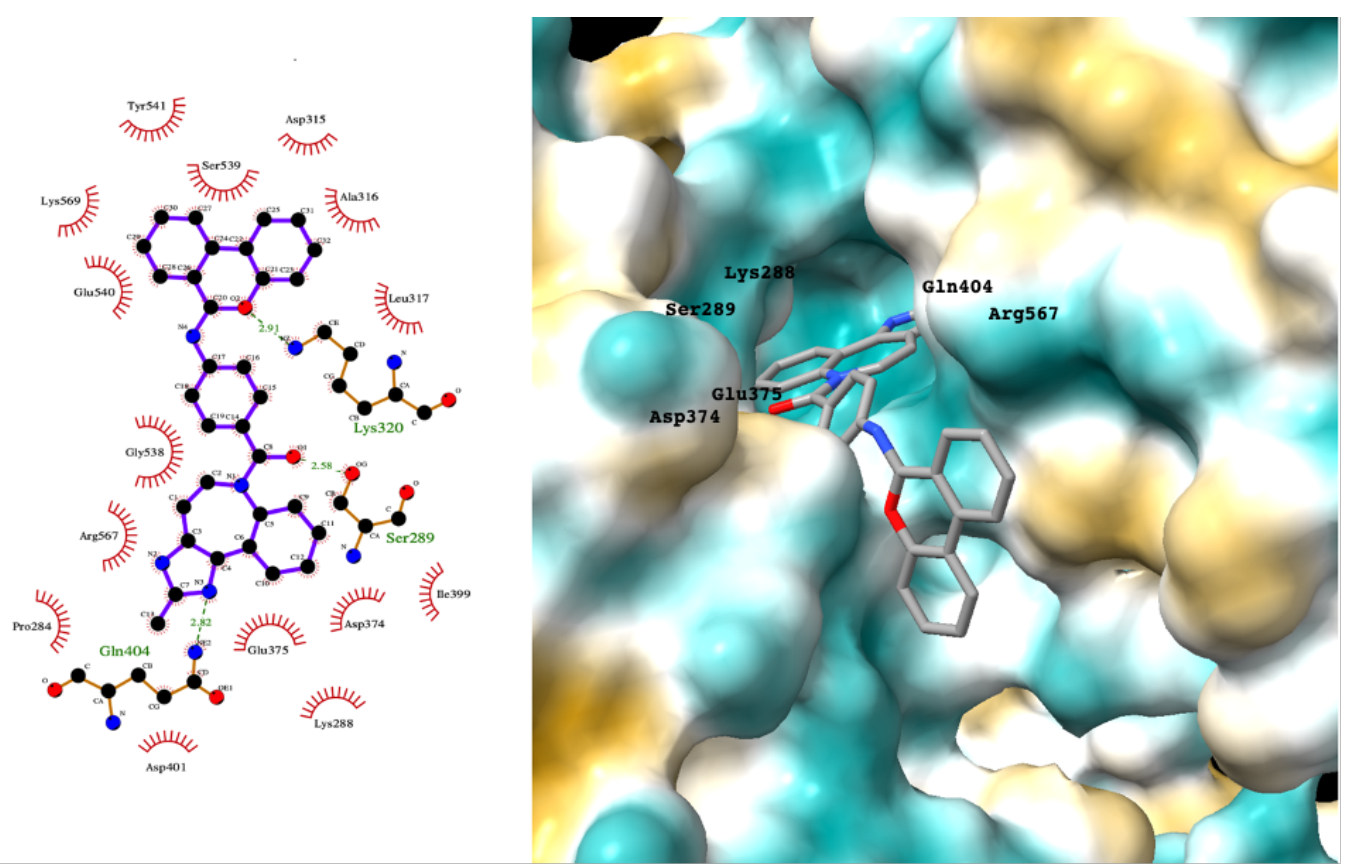

Figure 5. LigPlot (left) shows the key active site residues interacting with canivaptan. The molecular model (right) shows the binding of canivaptan to the active site cleft of the helicase. The tricyclic ring moiety is 
deeply embedded in a hydrophilic pocket. The molecular surface denotes hydrophobicity of the pockets (blue hydrophilic, yellow/brown hydrophobic). Positions of key binding site residues are labelled.

Aprepitant (NK1 antagonist) buries the morpholino ether moiety in the hydrophilic pocket and the hydrophobic bis trifluoromethyl substituted ring even deeper into this pocket. The environment mismatch is compensated by the favourable $\pi$-stacking and $\pi$-cation interactions referred to above.
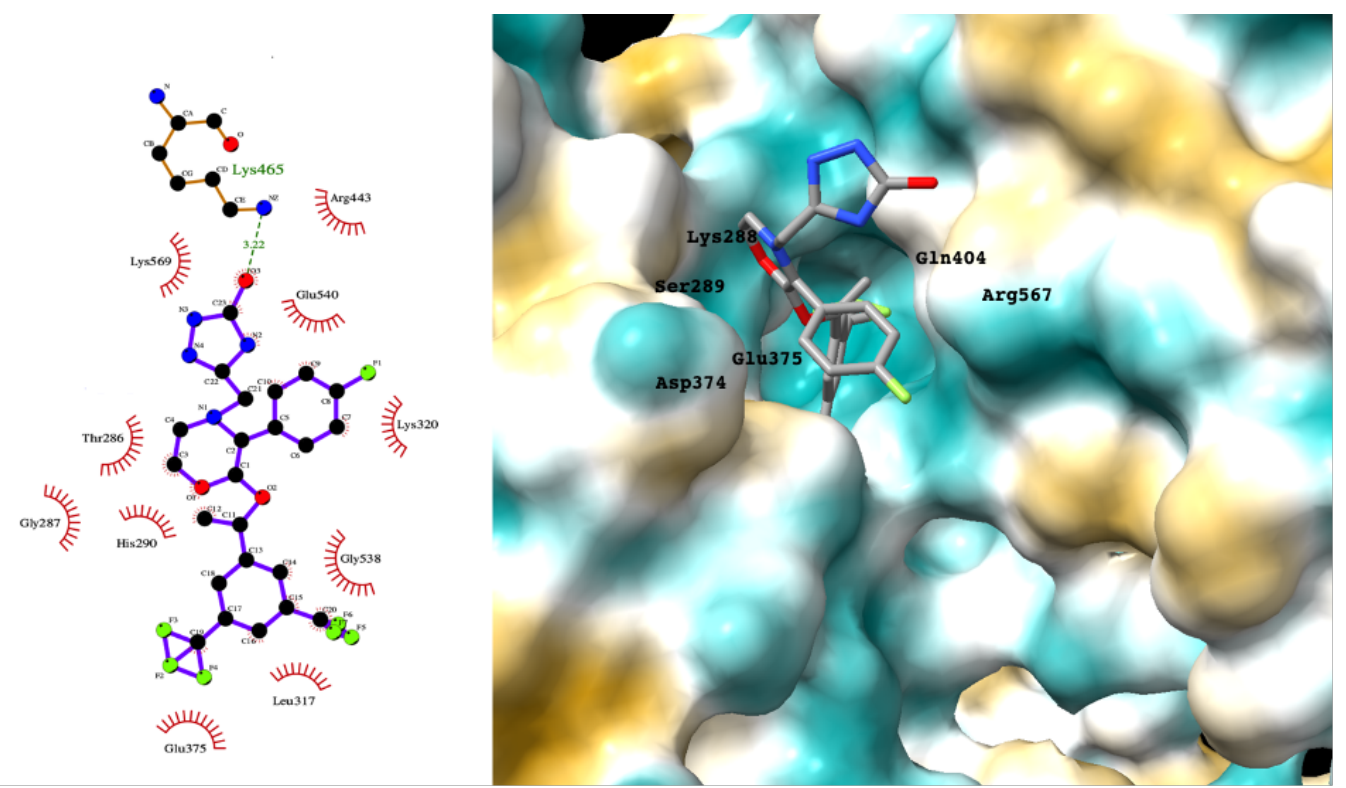

Figure 6. LigPlot (left) shows the key active site residues interacting with aprepitant. The molecular model (right) shows the binding of aprepitant to the active site cleft of the helicase. The molecular surface denotes hydrophobicity of the pockets (blue hydrophilic, yellow/brown hydrophobic). Positions of key binding site residues are labelled.

\section{Discussion}

\section{Other relevant computational studies on top 20 repurposed candidates}

The only prior computational study that proposed that our top-ranked drug candidate dolutegravir may inhibit SARS-CoV-2 helicase, involved a deep learning mode ${ }^{21}$. This study suggested that dolutegravir also inhibits several other viral targets. Indu et al. also used MD studies and Autodock Vina to identify dolutegravir as a potential inhibitor of SARS-CoV- $2 \mathrm{M}^{\text {pro }}$ and $\mathrm{RdRp}{ }^{22}$. If these activities of dolutegravir are subsequently confirmed, its ability to hit several viral targets simultaneously may make it particularly effective for treating COVID-19 patients. For example, such multitarget drug approaches have been very effective in controlling HIV infections.

Prior to this study, no reported computational studies reported that hesperidin, a citrus peel natural product, may inhibit SARS-CoV-2 helicase, although computational docking experiments by Adem et al. and Mosquer-Yuqui et al. identified hesperidin as a potential treatment ${ }^{23,24}$. Adem et al. used Molegro Virtual Docker 7 to analyze 80 flavonoid compounds binding to $\mathrm{M}^{\text {pro }}$ and found hesperidin had the highest predicted binding affinity ${ }^{23}$. Similarly, Mosquer-Yuqui et al. screened 92 phytochemicals from Andean medicinal plants against SARS-CoV-2 $\mathrm{M}^{\text {pro }}$ and RNA-dependent RNA polymerase (RdRp) using molecular docking ${ }^{24}$. Unlike Adem et al., they subsequently simulated the interactions of the top-ranked natural products, including hesperidin, using GROMACS MD. Hesperidin was also suggested as an antiviral candidate by other studies ${ }^{25-27}$. For example, Meneguzzo et al. reported that hesperidin had a high binding 
affinity to ACE2 and could block SARS-CoV-2 entry via this receptor (Figure 7), outperforming drugs already recommended for human Covid-19 trials ${ }^{27}$.

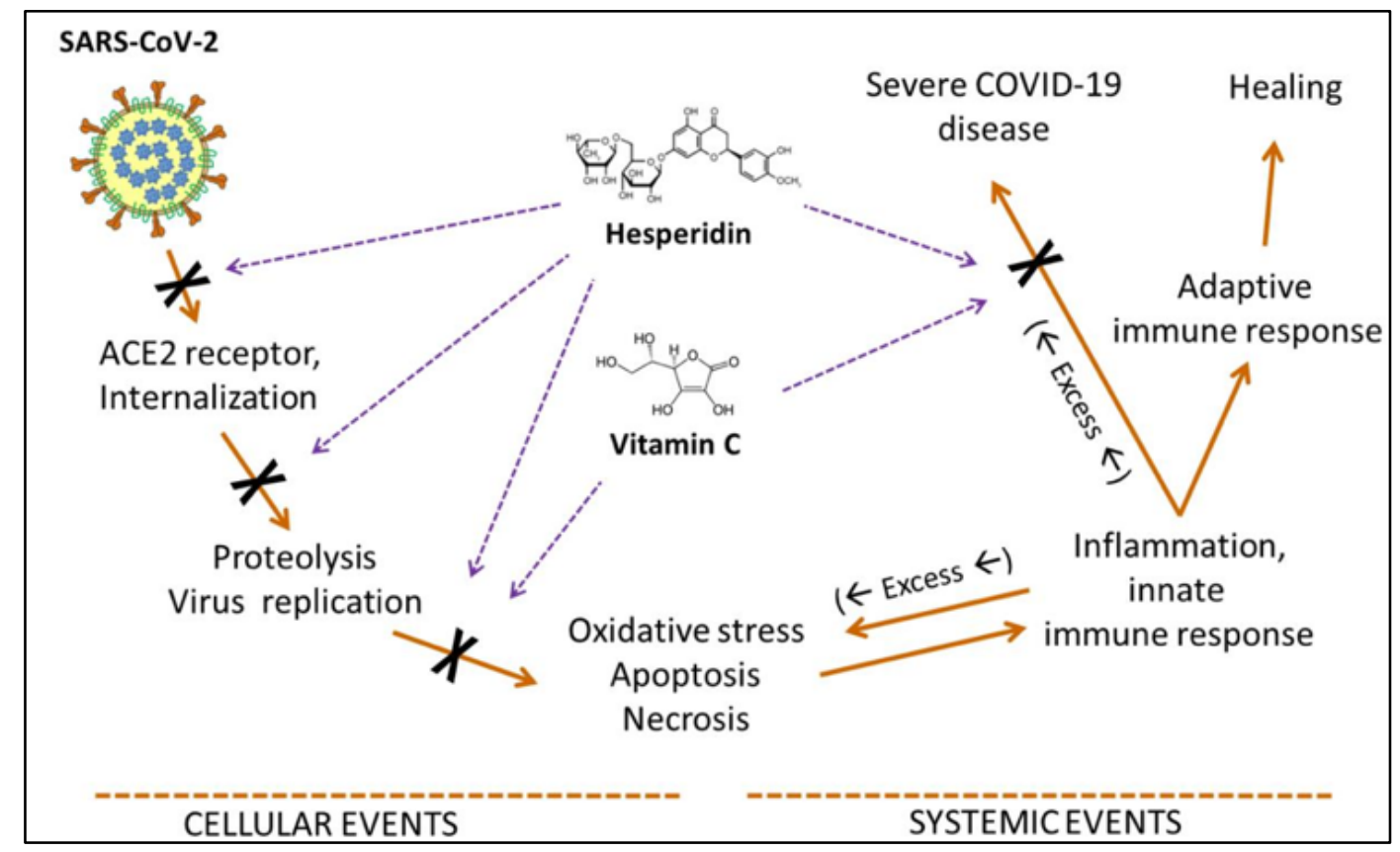

Figure 7. Multiple effects of hesperidin (coupled with ascorbic acid) on SARS-CoV-2 entry and replication, and systemic inflammation. Creative Commons Attribution (CC BY) license from Bellavite and Donzelli ${ }^{25}$.

There are also no prior reports of predicted activity of cabotegravir against the SARS-CoV-2 helicase, although Petersen et al. predicted that cabotegravir might bind to $\mathrm{M}^{\text {pro }}$ using a combination of molecular docking and MD calculations ${ }^{28}$. Similarly, no studies have reported conivaptan as having potential helicase activity, although Gul et al. predicted conivaptan would have activity against SARS-CoV-2 RdRp ${ }^{29}$. Potential conivaptan binding to the SARS-CoV-2 nsp9 replicase was found by Chandel et al. using a combination of Autodock screening followed by MD simulations ${ }^{30}$. Several other recent computational studies have also reported potential binding of conivaptan to various SARS-CoV-2 targets (see summary in Piplani et al. $)^{6,7}$.

Two prior studies predicted aprepitant (Emend) to be a helicase inhibitor. White et al. used Autodock Vina followed by MD simulations to identify aprepitant as having potential helicase activity ${ }^{11}$. Borgio et al. also identified aprepitant as having potential helicase activity using MOE molecular docking and the MOE score or GBVI/WSA binding free energies ${ }^{31}$.

Potential helicase activity of bictegravir has not been reported previously. However several computational docking studies identified bictegravir as having potential activity against the SARS-CoV-2 2'-O-ribose methyltransferase (2'-O-MTase) $)^{32}$, the spike glycoprotein ${ }^{33}$, and $\mathrm{M}^{\text {pro28. }}$.

Manidipine was predicted to be a promising binder to $\mathrm{M}^{\text {pro }}$ in a virtual screen using Glide SP, AutoDock Vina, and two protocols with AutoDock 4.2 followed by MD simulation using Gromacs ${ }^{34}$.

Tipranavir has been identified as a potential SARS-CoV-2 inhibitor in in vitro screens. No other computational studies have predicted tipranavir to be a helicase inhibitor. Kumar et al. reported potential activity against $\mathrm{M}^{\text {pro }}$ using docking with MD simulation ${ }^{35}$, whereas Gul et al., using a similar approach, suggested tipranavir would have activity of against both $\mathrm{M}^{\text {pro }}$ and $\mathrm{RdRp}{ }^{36}$. Autodock Vina was also used by Mohamed et al. to identify tipranavir as a potential inhibitor of SARS-CoV-2 PL ${ }^{\text {pro } 10}$. 
Activity of antrafenine against SARS-CoV-2 helicase was predicted by Wu et al. (Supplementary Table S1) using a homology model and the ICM 3.7.3 modelling software ${ }^{37}$. Mevada et al. used Autodock Vina to screen drug candidates against SARS-CoV-2, including against the helicase and antrafenine was shown to be potentially active against the helicase and many other targets, including the viral spike protein ${ }^{38}$. However, as no post-docking MD simulations were conducted on the lead molecules the results would need to be viewed with caution. Cozac et al. used machine learning and Autodock Vina calculations to predict antrafenine as an inhibitor of RdRp ${ }^{39}$.

In an earlier computational study, we identified RSV-604 as a potential SARS-CoV-2 $\mathrm{M}^{\text {pro }}$ inhibitor using Autodock Vina followed by MD simulation of the lead molecules in the active site of the protein ${ }^{5}$. Although no previous studies have predicted epirubicin to have activity against the SARS-CoV-2 helicase it has been identified as an inhibitor of chromodomain-helicase-DNA-binding protein 1 and HCV helicase ${ }^{40,41}$. No prior studies have reported activity of fluspirilene against the SARS-CoV-2 helicase, although it has been predicted to have activity against the SARS-CoV-2 nsp9 replicase ${ }^{42}$. Tam et al. reported it to have $\mathrm{M}^{\text {pro }}$ activity, and the DG of binding calculated by Autodock Vina correlated well with experimental DG of binding from the experimental $I C_{50}$ values of a range of putative antiviral agents ${ }^{43}$.

Fexofenadine was predicted to have good $\mathrm{M}^{\text {pro }}$ activity by Autodock Vina and to be a moderate binder by Autodock $^{44,45}$. Astemizole was also predicted to bind well to the SARS-CoV-2 spike protein by the PLANTS algorithm. It was in the top $2 \%$ of molecules that were rescored using MD (Amber and the Nwat-MMGBSA method $)^{46,47}$. It was also predicted to bind to the viral RdRp with high affinity using Autodock Vina ${ }^{48}$. Our earlier studies predicted sertindole to be a strong binder to SARS-CoV-2 RdRp ${ }^{6,7}$, and the activity of sertindole against $\mathrm{M}^{\text {pro }}$ also was later reported by Vatensever et al. ${ }^{44}$.

\section{Experimental validation of computational predictions for top 20 repurposed candidates}

Xie et al. reported a nanoluciferase assay in Vero $\mathrm{E} 6$ cells for SARS-CoV-2 that returned an $\mathrm{EC}_{50}>10 \mu \mathrm{M}$ and $\mathrm{CC}_{50}>50 \mu \mathrm{M}$ for bictegravir ${ }^{49}$. This assay also found that remdesivir and chloroquine were highly active, although responses in human clinical trials have been less than impressive. However, remdesivir has received emergency use authorization for the treatment of Covid-19 infections.

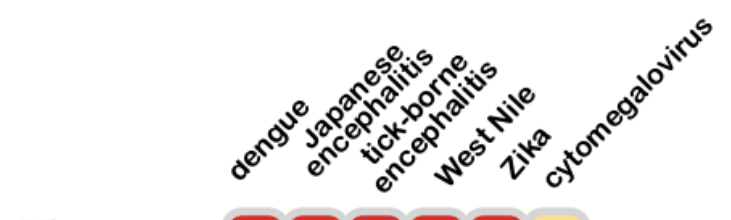

Virus group
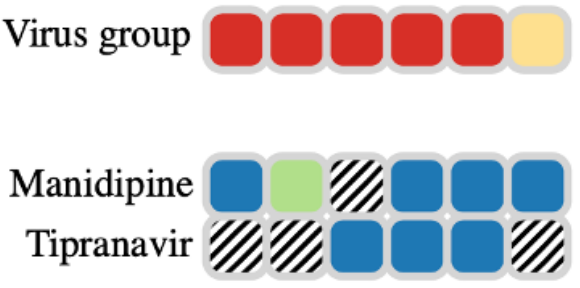

Figure 8. Experimental antiviral spectrum for hit compounds (cell assays (blue), animal model (green). From DrugVirus.info.

Manidipine has relatively broad-spectrum antiviral activity (see Figure 8), with in vitro $\mathrm{IC}_{50}$ values of $10 \mu \mathrm{M}$ against SARS-CoV-2 $\mathrm{M}^{\text {pro }}$ and $14 \mu \mathrm{M}$ against $\mathrm{PL}^{\text {pro }}$. It also exhibited antiviral activity against the SARS-CoV-2 virus with $\mathrm{EC}_{50}$ of $15 \pm 1 \mu \mathrm{M}$ in a plaque reduction assay ${ }^{50}$. Ghahremanpour et al. measured the activity of 
manidipine in a kinetic $\mathrm{M}^{\text {pro }}$ assay as $4.8 \mu \mathrm{M}$ and Pickard et al. measured its activity in $\mathrm{HUH7}$ cells $\left(\mathrm{IC}_{50}=2 \mu \mathrm{M}\right)$ and Vero cells $\left(\mathrm{IC}_{50}=7.5 \mu \mathrm{M}\right)^{51}$.

As summarized in Figure 8, tipranavir also exhibits a relatively broad spectrum of antiviral activity. It was shown to inhibit replication of SARS-CoV-2 in VeroE6 cells, but the SI was relatively low $\left(\mathrm{EC}_{50}=13 \mu \mathrm{M}, \mathrm{CC}_{50}\right.$ $=77 \mu \mathrm{M}, \mathrm{SI}=6)^{52}$. There are no experimental studies showing pimozide inhibits the SARS-CoV-2 helicase. Vatansever et al. identified pimozide as a basic molecule that raises endosomal $\mathrm{pH}$ to interfere with SARSCoV-2 entry into the human cell host, and measured an $\mathrm{IC}_{50}$ against $\mathrm{M}^{\mathrm{pro}}$ of $42 \pm 2 \mu \mathrm{M}^{44}$.

There is no published computational or experimental binding data for rutin binding to SARS-CoV-2 helicase, although Huynh et al., amongst several others, reported that MD calculations predicted rutin binding to $\mathrm{M}^{\text {pro } 53}$. Aprepitant, which was predicted by our study to have activity against the helicase, has been shown to be effective in treating severe to critical COVID-19 patients in combination with dexamethasone (clinicaltrials.gov (NCT04468646) $)^{54}$.

There are no reports in the literature of dicoumerol having activity against SARS-CoV-2, just a single report predicting binding to $\mathrm{M}^{\text {pro }}$ by Balakrishnan et al. ${ }^{55}$. Fluspirilene activity against SARS-CoV-2 was reported by Weston et al. They measured the $\mathrm{IC}_{50}$ as $3.1 \mu \mathrm{M}, \mathrm{CC}_{50}$ as $30.3 \mu \mathrm{M}$ and $\mathrm{SI}=10$ in Vero $\mathrm{E} 6$ cells $^{56}$. This mirrors the activity of fluspirilene against MERS-CoV and SARS-CoV in Vero E6 cells of $7.5 \mu \mathrm{M}$ and $6.0 \mu \mathrm{M}$, respectively ${ }^{57}$.

Doramapimod was reported to have an $\mathrm{IC}_{50}$ of $10 \mu \mathrm{M}$ against SARS-CoV-2 in MRC5-ACE2 cells, and showed synergism with remdesivir in killing the virus in vitro ${ }^{58}$. Astemizole was reported to have an $\mathrm{EC}_{50}$ of $1 \mu \mathrm{M}$ SARS-CoV-2 in Vero E6 cells, together with $\mathrm{EC}_{50}$ values against MERS-CoV and SARS-CoV of $4.9 \mu \mathrm{M}$ and $5.5 \mu \mathrm{M}$, respectively ${ }^{57,59}$.

\section{Experimental validation of predictions of the top 87 lead drugs}

Apart from the top 20 drug repurposing candidates with the highest predicted binding affinities to SARSCoV-2 helicase, a significant number of our other hits listed in Supplementary Table S1 also have published experimental validation of SARS-CoV-2 activity. Indeed, it is noteworthy that almost $30 \%$ of the drugs in our top 87 drug repurposing candidates have experimentally confirmed SARS-CoV-2 activity in vitro. While in vitro activity does not mean that all these drugs are operating by inhibiting the virus helicase or will have activity against the virus in vivo, this data shows that our computational screening method identified candidates that are highly enriched in compounds active against the virus. Our study suggests there is value in using in vitro assays to further screen the compounds in Supplementary Table S1 that have not yet been tested, to potentially yield additional existing drugs with unrecognized activity against SARS-CoV-2. As they are already approved drugs, any promising candidates can be rapidly advanced to human trials.

\section{Methods}

\section{Protein structure preparation and grid preparation}

The Protein Data Bank (PDB) file of the SARS-CoV-2 helicase 6XEZ (https://www.rcsb.org/structure/6XEZ) was obtained with a reported resolution of 2.90Å. Protein preparation, removal of non-essential and nonbridging water molecules, addition of hydrogen atoms and missing residues and loops for docking studies were performed using UCSF Chimera package (https://www.cgl.ucsf.edu/chimera/). ${ }^{60}$

\section{Screening databases}


Drugs were downloaded from the DrugBank database (FDA approved). A total of 11,875 drugs were retrieved from Drugbank. The drugs were downloaded in sdf format and converted to .pdbqt format using Raccoon. ${ }^{61}$

\section{Docking Methodology}

All unique small molecule drug structures were docked against the helicase protein structure using the AutoDock Vina (version 1.1.3) package ${ }^{61}$. AutoDock Vina employs a gradient-based conformational search approach and an energy-based empirical scoring function. AutoDock Vina is also flexible, easily scripted, extensively validated in many published studies with a variety of proteins and ligands and takes advantage of large multi-CPU or -GPU machines to run many calculations in parallel. The code has also been employed very successfully to dock millions of small molecule drug candidates into a series of protein targets to discover new potent drug leads. The package includes useful scripts for generating modified .pdb files required for grid calculations and for setting up the grid calculations around each protein automatically. AutoDock Tools (ADT) was used to prepare the required files for Autodock Vina. ${ }^{61}$ Non-essential heteroatoms, unnecessary protein chains or substructures (if any) and water molecules were removed, non-polar hydrogen atoms were added to the protein structure and structure converting to .pdbqt format. Binding pockets were predicted using castp (http://sts.bioe.uic.edu/castp) AutoDock Vina requires the removal of hydrogens, the addition of polar hydrogens, setting of the correct atom types, and calculation of atom charges compatible with the AutoGrid code. The algorithm generates a grid around each protein and calculates the interaction energy of a probe noble gas atom at each grid position outside and within the internal cavities of the protein. The grid size used was $137.6 \times 210.1 \times 135.1 \AA$. Grid resolution was set to 1 $\AA$, the maximum number of binding modes to output was fixed at 10 , and the exhaustiveness level (controlling the number of independent runs performed) was set at 8 . The docking calculations employed a genetic algorithm to optimize the binding conformations of the ligands during docking to the helicase site. Drugs were docked individually to the active site of the helicase with the grid coordinates (grid centre) and grid boxes of appropriate sizes generated by the bash script vina_screen.sh (Supplementary Information). The top-scoring compounds were identified with a python script script1.py (Supplementary Information) and subjected to molecular dynamics simulation. The docked structures were analysed using UCSF Chimera and LigPlot+ software to illustrate hydrogen-bond and hydrophobic interactions ${ }^{60,62}$. The 87 drugs from Drugbank database with the most favourable helicase binding energies were selected (see Supplementary Information). Molecular dynamics studies were subsequently conducted on this set of 87 compounds.

\section{Molecular Dynamics Simulations}

The top screened compound complexes with the helicase were minimized with CHARMm force field. The topology files of the ligands were prepared from Swissparam (http://www.swissparam.ch/) and minimized

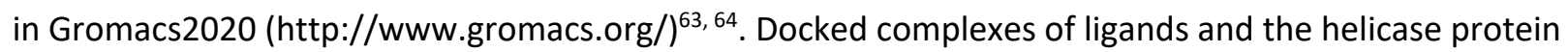
were used as starting geometries for MD simulations. Simulations were carried out using the GPU accelerated version of the program with the CHARMm force field I periodic boundary conditions in the ORACLE server. Docked complexes were immersed in a truncated octahedron box of TIP3P water molecules. The solvated box was further neutralized with $\mathrm{Na}+$ or $\mathrm{Cl}$-counter ions using the tleap program. Particle Mesh Ewald (PME) was employed to calculate the long-range electrostatic interactions. The cut-off distance for the long-range van der Waals (VDW) energy term was $12.0 \AA$. . The whole system was minimized without any restraint. The complexes were subjected to 2500 cycles of steepest descent minimization followed by 5000 cycles of conjugate gradient minimization. After system optimization, the MD simulations were initiated by gradually heating each system in the NVT ensemble from 0 to $300 \mathrm{~K}$ for 
50 ps using a Langevin thermostat with a coupling coefficient of $1.0 / \mathrm{ps}$ and with a force constant of $2.0 \mathrm{kcal} / \mathrm{mol} \cdot \AA 2 \mathrm{2}$ on the complex. Finally, a production run of $20 \mathrm{~ns}$ of MD simulation was performed under a constant temperature of $300 \mathrm{~K}$ in the NPT ensemble with periodic boundary conditions for each system. During the MD procedure, the SHAKE algorithm was used to constrain all covalent bonds involving hydrogen atoms. The time step was set to $2 \mathrm{fs}$. The structural stability of the complex was monitored by the RMSD and RMSF values of the backbone atoms of the entire protein. Calculations were also performed for up to $100 \mathrm{~ns}$ on a few compounds to ensure that $20 \mathrm{~ns}$ was sufficiently long for convergence. Duplicate production runs starting with different random seeds were also run to allow estimates of binding energy uncertainties to be obtained.

The binding free energies of the protein-ligand complexes were evaluated in two ways. The traditional method is to calculate the energies of solvated SARS-CoV-2 helicase and small molecule ligands and that of the bound complex and derive the binding energy by subtraction.

$\Delta G($ binding,$a q)=\Delta G($ complex, aq $)-(\Delta G$ (protein, aq $)+\Delta G$ (ligand, aq $)$

We also calculated binding energies using the molecular mechanics Poisson Boltzmann surface area (MM/PBSA) tool in GROMACS that is derived from the nonbonded interaction energies of the complex. The method is also widely used method for binding free energy calculations.

MMPBSA calculations were conducted by GMXPBSA 2.1 a suite based on Bash/Perl scripts for streamlining MMPBSA calculations on structural ensembles derived from GROMACS trajectories and to automatically calculate binding free energies for protein-protein or ligand-protein interactions ${ }^{65}$. GMXPBSA 2.1 calculates diverse MMPBSA energy contributions from molecular mechanics (MM) and electrostatic contribution to solvation (PB) and non-polar contribution to solvation (SA). This tool combines the capability of MD simulations (GROMACS) and the Poisson-Boltzmann equation (APBS) for calculating solvation energy (Baker et., 2001). The g_mmpbsa tool in GROMACS was used after molecular dynamics simulations, the output files obtained were used to post-process binding free energies by the singletrajectory MMPBSA method. In the current study, we used 100 frames at equal distances from 20ns trajectory files.

Specifically, for a non-covalent binding interaction in the aqueous phase the binding free energy, $\Delta \mathrm{G}$ (bind,aq), is: -

$$
\Delta \mathrm{G}(\text { bind }, \mathrm{aq})=\Delta \mathrm{G}(\text { bind }, \text { vac })+\Delta \mathrm{G} \text { (bind, solv) }
$$

where $\Delta G$ (bind,vac) is the binding free energy in vacuum, and $\Delta G$ (bind,solv) is the solvation free energy change upon binding:-

$$
\Delta \mathrm{G}(\text { bind, solv })=\Delta \mathrm{G}(\mathrm{R}: \mathrm{L}, \text { solv })-\Delta \mathrm{G}(\mathrm{R}, \text { solv })-\Delta \mathrm{G}(\mathrm{L}, \mathrm{solv})
$$

where $\Delta \mathrm{G}(\mathrm{R}: \mathrm{L}, \mathrm{solv}), \Delta \mathrm{G}(\mathrm{R}$,solv) and $\Delta \mathrm{G}(\mathrm{L}, \mathrm{solv})$ are solvation free energies of complex, receptor and ligand, respectively.

\section{Conclusions}

Here we show that the combination of advanced molecular docking algorithms with molecular dynamics simulations can reliably identify existing known drugs with potential activity against the SARS-CoV-2 helicase. These candidates, if confirmed, could then be rapidly deployed to treat COVID-19 patients in clinical trials. The predictions of our computational studies have largely been validated by parallel 
experimental in vitro testing by other groups. Given the high speed with which potential COVID-19 drug candidates can be identified using computational methods, the approach is highly suited for rapidly identifying promising drugs not just for the current pandemic but for those outbreaks that will inevitably occur in the future.

\section{Author Contributions}

Piplani: Data curation, Formal Analysis, Investigation, Methodology, Software, Validation, Visualization, Writing - original draft Singh: Data curation, Formal Analysis, Investigation, Methodology, Software, Validation, Visualization, Writing - original draft Winkler: Conceptualization, Formal Analysis, Investigation, Methodology, Project administration, Supervision, Validation, Visualization, Writing - original draft, Writing - review \& editing

Petrovsky: Conceptualization, Project administration, Resources, Software, Supervision, Validation, Visualization, Writing - original draft, Writing - review \& editing

All authors read and approved the final manuscript.

\section{Conflicts of interest}

There are no conflicts to declare.

\section{Acknowledgements}

We acknowledge the generous support of Oracle Cloud Systems for a grant of computing time, and the support of Alison Derbenwick-Miller, Peter Winn, and Dennis Ward in making these resources and software available.

\section{Notes and references}

1. Y. Huang, C. Yang, X.-f. Xu, W. Xu and S.-w. Liu, Acta Pharmacol. Sin., 2020, 41, 1141-1149.

2. N. Z. Cuervo and N. Grandvaux, Elife, 2020, 9, e61390.

3. J. Lan, J. Ge, J. Yu, S. Shan, H. Zhou, S. Fan, Q. Zhang, X. Shi, Q. Wang, L. Zhang and X. Wang, Nature, 2020, 581, 215-220.

4. R. Arya, S. Kumari, B. Pandey, H. Mistry, S. C. Bihani, A. Das, V. Prashar, G. D. Gupta, L. Panicker and M. Kumar, J Mol Biol, 2021, 433, 166725.

5. S. Piplani, P. Singh, N. Petrovsky and D. A. Winkler, arXiv, 2020.

6. S. Piplani, P. Singh, D. A. Winkler and N. Petrovsky, arXiv, 2020.

7. S. Piplani, P. Singh, D. A. Winkler and N. Petrovsky, Mol. Biomed., 2020.

8. J. Santos, S. Brierley, M. J. Gandhi, M. A. Cohen, P. C. Moschella and A. B. L. Declan, Viruses, 2020, 12, 705.

9. S. Dotolo, A. Marabotti, A. Facchiano and R. Tagliaferri, Brief. Bioinform., 2020, 22, 726-741.

10. K. Mohamed, N. Yazdanpanah, A. Saghazadeh and N. Rezaei, Bioorg. Chem., 2021, 106, 104490.

11. M. A. White, W. Lin and X. Cheng, J. Phys. Chem. Lett., 2020, 11, 9144-9151.

12. R. Martin, J. Li, A. Parvangada, J. Perry, T. Cihlar, H. Mo, D. Porter and E. Svarovskaia, Antiviral Res., 2021, 188, 105033.

13. J. Chen, B. Malone, E. Llewellyn, M. Grasso, P. M. M. Shelton, P. D. B. Olinares, K. Maruthi, E. Eng, H. Vatandaslar, B. T. Chait, T. Kapoor, S. A. Darst and E. A. Campbell, bioRxiv, 2020, DOI: 10.1101/2020.07.08.194084.

14. M. Prajapat, P. Sarma, N. Shekhar, P. Avti, S. Sinha, H. Kaur, S. Kumar, A. Bhattacharyya, H. Kumar, S. Bansal and B. Medhi, Ind. J. Pharmacol., 2020, 52, 56-65. 
15. M. A. Rohaim, R. F. El Naggar, E. Clayton and M. Munir, Microb. Pathogen., 2021, 150, 104641104641.

16. A. N. Spratt, F. Gallazzi, T. P. Quinn, C. L. Lorson, A. Sonnerborg and K. Singh, Expert Opin. Therapeut. Pat., 2021, DOI: 10.1080/13543776.2021.1884224.

17. J. A. Tanner, R. M. Watt, Y. B. Chai, L. Y. Lu, M. C. Lin, J. S. M. Peiris, L. L. M. Poon, H. F. Kung and J. D. Huang, J. Biol. Chem., 2003, 278, 39578-39582.

18. J. A. Newman, A. Douangamath, S. Yadzani, Y. Yosaatmadja, A. Aimon, J. Brandão-Neto, L. Dunnett, T. Gorrie-stone, R. Skyner, D. Fearon, M. Schapira, F. von Delft and O. Gileadi, Nat. Comm., 2021, 12,4848 .

19. H. Guterres and W. Im, J. Chem. Inf. Model., 2020, 60, 2189-2198.

20. D. A. Winkler, J. Chem. Inf. Model., 2020, 60, 4421-4423.

21. B. R. Beck, B. Shin, Y. Choi, S. Park and K. Kang, Comput. Struct. Biotechnol. J., 2020, 18, 784-790.

22. P. Indu, M. R. Rameshkumar, N. Arunagirinathan, N. A. Al-Dhabi, M. Valan Arasu and S. Ignacimuthu, J. Infect. Pub. Health, 2020, 13, 1856-1861.

23. S. Adem, V. Eyupoglu, I. Sarfraz, A. Rasul and M. Ali, Preprints, 2020, preprints202003.0333.v1.

24. F. Mosquera-Yuqui, N. Lopez-Guerra and E. A. Moncayo-Palacio, J. Biomol. Struct. Dyn., 2020, DOI: 10.1080/07391102.2020.1835716, 1-14.

25. P. Bellavite and A. Donzelli, Antioxid., 2020, 9, 742.

26. Y. A. Haggag, N. E. El-Ashmawy and K. M. Okasha, Med. Hypoth., 2020, 144, 109957.

27. F. Meneguzzo, R. Ciriminna, F. Zabini and M. Pagliaro, Processes, 2020, 8, 549.

28. L. Peterson, ChemRxiv, 2020, chemrxiv.12155523.v1.

29. S. Gul, O. Ozcan, A. Okyar, I. Barıs and I. H. Kavakli, J. Biomol. Struct. Dynam., 2020, DOI: 10.1080/07391102.2020.1802346, 1-20.

30. V. Chandel, P. P. Sharma, S. Raj, B. Rathi and D. Kumar, J. Biomol. Struct. Dynam., 2020, DOI: 10.1080/07391102.2020.1811773.

31. J. F. Borgio, H. S. Alsuwat, W. M. Al Otaibi, A. M. Ibrahim, N. B. Almandil, L. I. Al Asoom, M. Salahuddin, B. Kamaraj and S. AbdulAzeez, Arch. Med. Sci., 2020, 16, 508-518.

32. R. J. Khan, R. K. Jha, G. M. Amera, M. Jain, E. Singh, A. Pathak, R. P. Singh, J. Muthukumaran and A. K. Singh, J. Biomol. Struct. Dynam., 2020, DOI: 10.1080/07391102.2020.1753577, 1-14.

33. C. Sun, J. Zhang, J. Wei, X. Zheng, X. Zhao, Z. Fang, D. Xu, H. Yuan and Y. Liu, PloS One, 2021, 16, e0245975.

34. M. M. Ghahremanpour, J. Tirado-Rives, M. Deshmukh, J. A. Ippolito, C. H. Zhang, I. Cabeza de Vaca, M. E. Liosi, K. S. Anderson and W. L. Jorgensen, ACS Med Chem Lett, 2020, 11, 2526-2533.

35. Y. Kumar, H. Singh and C. N. Patel, J. Infect. Public Health, 2020, 13, 1210-1223.

36. S. Gul, O. Ozcan, S. Asar, A. Okyar, I. Baris and I. H. Kavakli, J. Biomol. Struct. Dynam., 2020, DOI: 10.1080/07391102.2020.1802346, in press.

37. C. Wu, Y. Liu, Y. Yang, P. Zhang, W. Zhong, Y. Wang, Q. Wang, Y. Xu, M. Li, X. Li, M. Zheng, L. Chen and H. Li, Acta Pharmaceut. Sin. B, 2020, 10, 766-788.

38. V. Mevada, P. Dudhagara, H. Gandhi, N. Vaghamshi, U. Beladiya and R. Patel, ChemRxiv, 2020, 10.26434/chemrxiv.12115251.v2.

39. R. Cozac, N. Medzhidov and S. Yuk, arXiv, 2020, arXiv:2006.06523.

40. A. M. Boguszewska-Chachulska, M. Krawczyk, A. Stankiewicz, A. Gozdek, A.-L. Haenni and L. Strokovskaya, FEBS Lett., 2004, 567, 253-258.

41. N. Panera, A. E. Tozzi and A. Alisi, Drugs, 2020, 80, 941-946.

42. A. Chandra, V. Gurjar, M. Z. Ahmed, A. S. Alqahtani, I. Qamar and N. Singh, J. Biomol. Struct. Dynam., 2021, DOI: 10.1080/07391102.2020.1871416, 1-8. 
43. N. M. Tam, P. C. Nam, D. T. Quang, N. T. Tung, V. V. Vu and S. T. Ngo, RSC Adv., 2021, 11, 29262934.

44. E. C. Vatansever, K. S. Yang, A. K. Drelich, K. C. Kratch, C.-C. Cho, K. R. Kempaiah, J. C. Hsu, D. M. Mellott, S. Xu, C.-T. K. Tseng and W. R. Liu, Proc. NatI. Acad. Sci. USA, 2021, 118, e2012201118.

45. B. Nautiyal, A. Kumar and J. K. Malik, Saudi J. Med. Pharm. Sci., 2020, 6, 712-716.

46. I. Maffucci and A. Contini, J Proteome Res, 2020, 19, 4637-4648.

47. I. Maffucci, X. Hu, V. Fumagalli and A. Contini, Front Chem, 2018, 6, 43.

48. S. Khater, N. Dasgupta and G. Das, Front. Microbiol., 12, 1934.

49. X. Xie, A. E. Muruato, X. Zhang, K. G. Lokugamage, C. R. Fontes-Garfias, J. Zou, J. Liu, P. Ren, M. Balakrishnan, T. Cihlar, C.-T. K. Tseng, S. Makino, V. D. Menachery, J. P. Bilello and P.-Y. Shi, bioRxiv, 2020, 2020.06.22.165712.

50. C. J. Kuo, T. L. Chao, H. C. Kao, Y. M. Tsai, Y. K. Liu, L. H. Wang, M. C. Hsieh, S. Y. Chang and P. H. Liang, Antimicrob. Agents Chemother., 2021, DOI: 10.1128/AAC.02577-20.

51. A. Pickard, B. C. Calverley, J. Chang, R. Garva, Y. Lu and K. E. Kadler, bioRxiv, 2021, 2021.01.31.428851.

52. N. Yamamoto, S. Matsuyama, T. Hoshino and N. Yamamoto, bioRxiv, 2020, DOI: 10.1101/2020.04.06.026476, 2020.2004.2006.026476.

53. T. Huynh, H. Wang and B. Luan, Phys. Chem. Chem. Phys., 2020, 22, 25335-25343.

54. R. Mehboob, F. J. Ahmad, A. Qayyum, M. A. Rana, S. A. Gilani, M. A. Tariq, G. Ali, S. J. Akram and J. Akram, medRxiv, 2020, DOI: 10.1101/2020.08.01.20166678, 2020.2008.2001.20166678.

55. V. Balakrishnan and K. Lakshminarayanan, Int. J. Peptide Res. Therapeut., 2021, 27, 651-658

56. S. Weston, C. M. Coleman, R. Haupt, J. Logue, K. Matthews and M. B. Frieman, bioRxiv, 2020, DOI: 10.1101/2020.03.25.008482, 2020.2003.2025.008482.

57. J. Dyall, C. M. Coleman, B. J. Hart, T. Venkataraman, M. R. Holbrook, J. Kindrachuk, R. F. Johnson, G. G. Olinger, P. B. Jahrling, M. Laidlaw, L. M. Johansen, C. M. Lear-Rooney, P. J. Glass, L. E. Hensley and M. B. Frieman, Antimicrob. Agents Chemother., 2014, 58, 4885-4893.

58. M. H. Raymonda, J. H. Ciesla, M. Monaghan, J. Leach, G. Asantewaa, L. A. Smorodintsev-Schiller, M. M. Lutz, X. L. Schafer, T. Takimoto, S. Dewhurst, J. Munger and I. S. Harris, bioRxiv, 2020, DOI: 10.1101/2020.11.25.398859, 2020.2011.2025.398859.

59. L. Riva, S. Yuan, X. Yin, L. Martin-Sancho, N. Matsunaga, S. Burgstaller-Muehlbacher, L. Pache, P. P. De Jesus, M. V. Hull, M. Chang, J. F. Chan, J. Cao, V. K. Poon, K. Herbert, T. T. Nguyen, Y. Pu, C. Nguyen, A. Rubanov, L. Martinez-Sobrido, W. C. Liu, L. Miorin, K. M. White, J. R. Johnson, C. Benner, R. Sun, P. G. Schultz, A. Su, A. Garcia-Sastre, A. K. Chatterjee, K. Y. Yuen and S. K. Chanda, bioRxiv, 2020, DOI: 10.1101/2020.04.16.044016.

60. E. F. Pettersen, T. D. Goddard, C. C. Huang, G. S. Couch, D. M. Greenblatt, E. C. Meng and T. E. Ferrin, J Comput Chem, 2004, 25, 1605-1612.

61. S. Forli, R. Huey, M. E. Pique, M. F. Sanner, D. S. Goodsell and A. J. Olson, Nat Protoc, 2016, 11, 905919.

62. R. A. Laskowski and M. B. Swindells, J Chem Inf Model, 2011, 51, 2778-2786.

63. V. Zoete, M. A. Cuendet, A. Grosdidier and O. Michielin, J Comput Chem, 2011, 32, 2359-2368.

64. M. J. Abraham, T. Murtola, R. Schulz, S. Páll, J. C. Smith, B. Hess and E. Lindahl, SoftwareX, 2015, 12, 19-25.

65. C. Paissoni, D. Spiliotopoulos, G. Musco and A. Spitaleri, Comp. Phys. Comm., 2015, 186, 105-107. 


\section{Putative COVID-19 therapies from computational repurposing of drugs and natural products against the SARS-CoV-2 helicase}

Sakshi Pilani ${ }^{1,2}$, Puneet Singh ${ }^{2}$, David A. Winkler ${ }^{3,4,5}$, Nikolai Petrovsky ${ }^{1,2}$

1 College of Medicine and Public Health, Flinders University, Bedford Park 5046, Australia

2 Vaxine Pty Ltd, 11 Walkley Avenue, Warradale 5046, Australia

3 La Trobe University, Kingsbury Drive, Bundoora 3042, Australia

4 Monash Institute of Pharmaceutical Sciences, Monash University, Parkville 3052, Australia

5 School of Pharmacy, University of Nottingham, Nottingham NG7 2RD. UK 
Table S1. Binding energies and published SARS-Cov-2 data for 88 top ranked small molecule ligands

\begin{tabular}{|c|c|c|c|c|c|}
\hline No. & $\begin{array}{l}\text { Drugbank } \\
\text { ID }\end{array}$ & Name & $\begin{array}{c}\Delta \mathrm{G}_{\text {MMPBSA }} \\
\mathrm{kcal} / \mathrm{mol}\end{array}$ & $\begin{array}{l}\Delta \mathrm{G}_{\text {thermo }} \\
\mathrm{kcal} / \mathrm{mol}\end{array}$ & Experimental SARS-CoV-2 data \\
\hline 1 & DB08930 & Dolutegravir & -42.15 & -45.87 & SARS-CoV-2 activity in Vero cells $\mathrm{EC}_{50}=22 \mu \mathrm{M}, \mathrm{CC}_{50}>40 \mu \mathrm{M}^{1}$ \\
\hline 2 & DB04703 & Hesperidin & -41.23 & -39.58 & SARS-Cov-2 Mpro inhibition $\mathrm{IC}_{50}=8.3 \mu \mathrm{M}^{2}$ \\
\hline 3 & DB11751 & Cabotegravir & -40.77 & -42.31 & $\ldots$ \\
\hline 4 & DB00872 & Conivaptan & -40.20 & -39.65 & $\begin{array}{l}\text { SARS-CoV-2 EC50 } 10 \mu \mathrm{M} \mathrm{CC}_{50} 13 \mu \mathrm{M} \text { in HEK-293T cells. }{ }^{3} \mathrm{EC}_{50}=12.2 \mu \mathrm{M} \text { against HCoV- } \\
\text { OC43. }\end{array}$ \\
\hline 5 & DB00673 & Aprepitant & -40.12 & -45.58 & $\ldots$ \\
\hline 6 & DB11799 & Bictegravir & -39.78 & -41.22 & $\begin{array}{l}\text { Vero E6 cells for SARS-CoV-2 that returned an } \mathrm{EC}_{50}>10 \mu \mathrm{M} \text { and } \mathrm{CC}_{50}>50 \mu \mathrm{M} \text { for } \\
\text { bictegravir. }{ }^{4}\end{array}$ \\
\hline 7 & DB09238 & Manidipine & -39.77 & -41.25 & $\begin{array}{l}\mathrm{IC}_{50} 10 \mu \mathrm{M} \text { against SARS-CoV- } 2 \mathrm{M}^{\mathrm{pro}} ; 14 \mu \mathrm{M} \text { against } \mathrm{PL}^{\mathrm{pro}} . \text { Apparent SARS-CoV-2 } \mathrm{EC}_{50}= \\
15 \pm 1 \mu \mathrm{M} \text { in a plaque reduction assay. }{ }^{5} \text { et al. Kinetic } \mathrm{M}^{\text {pro }} \mathrm{IC}_{50}=4.8 \mu \mathrm{M} \text {. SARS-CoV-2 } \\
\text { activity in in HUH7 cells }\left(\mathrm{IC}_{50}=2 \mu \mathrm{M}\right) \text { and Vero cells }\left(\mathrm{IC}_{50}=7.5 \mu \mathrm{M}\right) .{ }^{6}\end{array}$ \\
\hline 8 & DB00932 & Tipranavir & -39.74 & -42.56 & $\begin{array}{l}\text { Inhibits replication of SARS-CoV-2 in VeroE6 cells, but low } \mathrm{SI}\left(\mathrm{EC}_{50}=13 \mu \mathrm{M}, \mathrm{CC}_{50}=77\right. \\
\mu \mathrm{M}, \mathrm{SI}=6)^{7}\end{array}$ \\
\hline 9 & DB04452 & Aminoquinuride & -39.58 & -41.89 & $\ldots$ \\
\hline 10 & DB01419 & Antrafenine & -39.14 & -36.47 & $\ldots$ \\
\hline 11 & DB15197 & RSV-604 & -38.75 & -36.21 & $\ldots$ \\
\hline
\end{tabular}




\begin{tabular}{|c|c|c|c|c|c|}
\hline No. & $\begin{array}{l}\text { Drugbank } \\
\text { ID }\end{array}$ & Name & $\begin{array}{c}\Delta \mathrm{G}_{\text {MMPBSA }} \\
\mathrm{kcal} / \mathrm{mol}\end{array}$ & $\begin{array}{l}\Delta \mathrm{G}_{\text {thermo }} \\
\mathrm{kcal} / \mathrm{mol}\end{array}$ & Experimental SARS-CoV-2 data \\
\hline 12 & DB004445 & Epirubicin & -38.74 & -35.62 & .. \\
\hline 13 & DB01100 & Pimozide & -38.36 & -35.44 & $\mathrm{IC}_{50}$ for SARS-CoV-2 $\mathrm{M}^{\mathrm{pro}}=42 \pm 2 \mu \mathrm{M}^{8}$ \\
\hline 14 & DB01698 & Rutin & -38.32 & -40.44 & $\mathrm{IC}_{50}=32 \mu \mathrm{M}$ for SARS-CoV-2 $\mathrm{M}^{\text {pro }} \cdot{ }^{9}$ \\
\hline 15 & DB00266 & Dicoumarol & -37.56 & -38.39 & .. \\
\hline 16 & DB04842 & Fluspirilene & -36.77 & -38.38 & $\begin{array}{l}\mathrm{IC}_{50}=3.1 \mu \mathrm{M} \text { and } \mathrm{CC}_{50}=30.3 \mu \mathrm{M} \text { with } \mathrm{SI}=10 \text { in Vero E6 cells. }{ }^{10} \text { In vitro activity in MERS- } \\
\mathrm{CoV} \text { and SARS-CoV-1 }(\mathrm{SARS})=7.5 \mu \mathrm{M} \text { and } 6.0 \mu \mathrm{M} \text { respectively in Vero E6 cells. }{ }^{11}\end{array}$ \\
\hline 17 & DB03044 & Doramapimod & -36.21 & -39.45 & $\begin{array}{l}\mathrm{IC}_{50}=10 \mu \mathrm{M} \text { against SARS-CoV-2 in MRC5-ACE2 cells. Useful synergism with remdesivir } \\
\text { in killing the virus in vitro. }{ }^{12}\end{array}$ \\
\hline 18 & DB00950 & Fexofenadine & -35.47 & -37.66 & $\cdots$ \\
\hline 19 & DB00637 & Astemizole & -35.35 & -38.70 & $\begin{array}{l}\mathrm{EC}_{50}=1 \mu \mathrm{M} \text { in Vero E6 cells infected with SARS-CoV-2. }{ }^{13} \mathrm{EC}_{50} \text { values for MERS-CoV and } \\
\text { SARS-CoV-1 (SARS) of } 4.9 \mu \mathrm{M} \text { and } 5.5 \mu \mathrm{M} \text { respectively. }{ }^{11}\end{array}$ \\
\hline 20 & DB01100 & Pimozide & -34.67 & -38.21 & SARS-CoV-2 $\mathrm{M}^{\mathrm{pro}} \mathrm{IC}_{50}=42 \mu \mathrm{M}^{8}$ \\
\hline 21 & DB06144 & Sertindole & -34.56 & -36.77 & $\cdots$ \\
\hline 22 & DB12580 & Tradipitant & -34.21 & -32.11 & Phase 3 clinical trial for COVID-19 NCT04326426. ${ }^{14}$ \\
\hline 23 & DB08881 & Vemurafenib & -33.78 & -30.25 & SARS-CoV-2 in vitro inhibition in Vero cells, $\mathrm{IC}_{50}=7.0 \mu \mathrm{M}$ and $\mathrm{CC}_{50}>50 \mu \mathrm{M}^{15}$ \\
\hline 24 & DB09295 & Talniflumate & -33.22 & -31.47 & $\cdots$ \\
\hline 25 & DB09048 & Netupitant & -32.45 & -30.74 & $\ldots$ \\
\hline
\end{tabular}




\begin{tabular}{|c|c|c|c|c|c|}
\hline No. & $\begin{array}{l}\text { Drugbank } \\
\quad \text { ID }\end{array}$ & Name & $\begin{array}{c}\Delta \mathrm{G}_{\mathrm{MMPBSA}} \\
\mathrm{kcal} / \mathrm{mol}\end{array}$ & $\begin{array}{l}\Delta \mathrm{G}_{\text {thermo }} \\
\mathrm{kcal} / \mathrm{mol}\end{array}$ & Experimental SARS-CoV-2 data \\
\hline 26 & DB11759 & Penvonedistat & -32.44 & -35.41 & .. \\
\hline 27 & DB00966 & Telmisartan & -32.31 & -35.08 & $\ldots$ \\
\hline 28 & DB09298 & Silibinin & -32.26 & -30.41 & .. \\
\hline 29 & DB11995 & Avatrombopag & -31.52 & -35.47 & .. \\
\hline 30 & DB12877 & Oxatomide & -31.41 & -30.47 & In vitro SARS-CoV-2 inhibition in Vero CCL-81 cells $\mathrm{IC}_{50} 25 \mu \mathrm{M}$ and $\mathrm{CC}_{50}=40 \mu \mathrm{M} .^{16}$ \\
\hline 31 & DB06555 & Siramesine & -30.47 & -31.53 & ... \\
\hline 32 & DB14883 & Lorecivivint & -30.41 & -32.96 & ... \\
\hline 33 & DB03966 & Clorobiocin & -29.60 & -31.92 & .. \\
\hline 34 & DB12306 & Cipargamin & -29.47 & -30.45 & $\ldots$ \\
\hline 35 & DB12566 & Decernotinib & -29.31 & -24.74 & $\cdots$ \\
\hline 36 & DB01260 & Desonide & -29.18 & -29.15 & $\ldots$ \\
\hline 37 & DB11925 & Vistusertib & -28.97 & -25.23 & SARS-CoV-2 activity in Vero E6 cells, $\mathrm{IC}_{50}<25 \mathrm{nM}^{17}$ \\
\hline 38 & DB13791 & Penfluridol & -28.75 & -30.41 & $\begin{array}{l}\text { SARS-CoV-2 in vitro activity in Vero CCL-81 cells, } \mathrm{EC}_{50} 1.9 \mu \mathrm{M} \text { and } \mathrm{CC}_{50}=3.3 \mu \mathrm{M} .^{16} \mathrm{In} \\
\text { vitro activity in Vero E6 cells with } \mathrm{IC}_{50}=2.4 \mu \mathrm{M} \text { and } \mathrm{CC}_{50}=12.9 \mu \mathrm{M} .{ }^{18}\end{array}$ \\
\hline 39 & DB15583 & Fluazuron & -28.24 & -31.42 & $\cdots$ \\
\hline 40 & DB07138 & Neflamapimod & -28.03 & -30.38 & $\cdots$ \\
\hline 41 & DB12703 & Omipalisib & -27.98 & -24.36 & $\ldots$ \\
\hline
\end{tabular}




\begin{tabular}{|c|c|c|c|c|c|}
\hline No. & $\begin{array}{c}\text { Drugbank } \\
\text { ID }\end{array}$ & Name & $\begin{array}{l}\Delta \mathrm{G}_{\mathrm{MMPBSA}} \\
\mathrm{kcal} / \mathrm{mol}\end{array}$ & $\begin{array}{l}\Delta \mathrm{G}_{\text {thermo }} \\
\mathrm{kcal} / \mathrm{mol}\end{array}$ & Experimental SARS-CoV-2 data \\
\hline 42 & DB12264 & Atevirdine & -27.89 & -29.33 & .. \\
\hline 43 & DB13434 & Fenticonazole & -27.87 & -23.12 & ... \\
\hline 44 & DB13074 & Macimorelin & -27.84 & -22.34 & .. \\
\hline 45 & DB00342 & Terfenadine & -27.33 & -28.88 & SARS-CoV-2 $\mathrm{IC}_{50}=3.0 \mu \mathrm{M}$ in Vero cells. ${ }^{19}$ \\
\hline 46 & DB11616 & Pirarubicin & -26.74 & -26.33 & $\mathrm{IC}_{50}=4-7 \mu \mathrm{M}$ in nsp15 FRET assay. ${ }^{20}$ \\
\hline 47 & DB01349 & Tasosartan & -26.32 & -26.44 & .. \\
\hline 48 & DB15630 & Glumetinib & -26.10 & -24.85 & .. \\
\hline 49 & DB00547 & Desoximetasone & -26.09 & -25.29 & $\ldots$ \\
\hline 50 & DB11977 & Golvatinib & -25.65 & -28.45 & $\ldots$ \\
\hline 51 & DB06589 & Pazopanib & -25.58 & -25.14 & $\ldots$ \\
\hline 52 & DB00568 & Cinnarizine & -25.54 & -25.10 & SARS-CoV-2 activity in Vero CCL-81 cells, $\mathrm{EC}_{50}=40 \mu \mathrm{M}, \mathrm{CC}_{50}=100 \mu \mathrm{M} .^{16}$ \\
\hline 53 & DB11830 & Mocetinostat & -25.45 & -27.99 & $\ldots$ \\
\hline 54 & DB00619 & Imatinib & -25.36 & -27.87 & $\begin{array}{l}\text { Inhibits SARS-CoV-2 with an } \mathrm{IC}_{50}=130 \mathrm{nM} \text { in Vero cells. }{ }^{21} \mathrm{EC}_{50}=2.5 \mu \mathrm{M}, \mathrm{CC}_{50}>40 \mu \mathrm{M} \text { in } \\
\text { Vero E6 cells. }^{22} \mathrm{SARS}-\mathrm{CoV}-2 \mathrm{EC}_{50}=4.9 \mu \mathrm{M}, \mathrm{IC}_{50}=37.3 \mu \mathrm{M} \text { by luciferase assay in lung } \\
\text { organoids. }^{23}\end{array}$ \\
\hline 55 & DB12427 & Orvepitant & -25.36 & -22.78 & $\ldots$ \\
\hline 56 & DB14895 & Vibegron & -24.88 & -20.32 & $\ldots$ \\
\hline
\end{tabular}




\begin{tabular}{|c|c|c|c|c|c|}
\hline No. & $\begin{array}{l}\text { Drugbank } \\
\text { ID }\end{array}$ & Name & $\begin{array}{c}\Delta \mathrm{G}_{\mathrm{MMPBSA}} \\
\mathrm{kcal} / \mathrm{mol}\end{array}$ & $\begin{array}{l}\Delta \mathrm{G}_{\text {thermo }} \\
\mathrm{kcal} / \mathrm{mol}\end{array}$ & Experimental SARS-CoV-2 data \\
\hline 57 & DB13248 & Phthalylsulfathiazole & -24.52 & -26.74 & .. \\
\hline 58 & DB13005 & Rebastinib & -24.51 & -22.52 & .. \\
\hline 59 & DB06660 & Saredutant & -24.48 & -22.45 & .. \\
\hline 60 & DB11986 & Entrectinib & -24.23 & -27.12 & .. \\
\hline 61 & DB09003 & Clocapramine & -24.22 & -20.58 & $\ldots$ \\
\hline 62 & DB06446 & Dotarizine & -24.13 & -20.33 & .. \\
\hline 63 & DB09143 & Sonidegib & -24.11 & -21.20 & .. \\
\hline 64 & DB06077 & Lumateperone & -23.87 & -20.96 & .. \\
\hline 65 & DB06638 & Quarfloxin & -23.56 & -27.18 & .. \\
\hline 66 & DB13919 & Candesartan & -23.21 & -27.33 & $\begin{array}{l}\text { Inhibits human coronavirus }(\mathrm{HCoV}) \text { strain OC43 propagated in LLC-MK2 cells, } \mathrm{IC}_{50}= \\
3.6 \mu \mathrm{M}, \mathrm{CC}_{50} \sim 10 \mu \mathrm{M}^{3}\end{array}$ \\
\hline 67 & DB15391 & Elenbecestat & -23.12 & -25.63 & .. \\
\hline 68 & DB08901 & Ponatinib & -22.89 & -27.03 & $\begin{array}{l}\text { Inhibition of SARS-CoV-2 in Huh7 cells engineered with the human ACE-2 receptor using } \\
\text { immunofluorescence, } \mathrm{EC}_{50}=1.1 \mu \mathrm{M}, \mathrm{CC}_{50}=8.7 \mu \mathrm{M}^{24}\end{array}$ \\
\hline 69 & DB12412 & Gemigliptin & -22.88 & -20.79 & .. \\
\hline 70 & DB12978 & Pexidartinib & -22.87 & -20.23 & SARS-CoV-2 inhibition $\mathrm{IC}_{50}=5.4 \mu \mathrm{M}$ in Caco-2 cells. ${ }^{25}$ \\
\hline 71 & DB04908 & Flibanserin & -22.47 & -19.25 & $\ldots$ \\
\hline
\end{tabular}




\begin{tabular}{|c|c|c|c|c|c|}
\hline No. & $\begin{array}{l}\text { Drugbank } \\
\quad \text { ID }\end{array}$ & Name & $\begin{array}{c}\Delta \mathrm{G}_{\mathrm{MMPBSA}} \\
\mathrm{kcal} / \mathrm{mol}\end{array}$ & $\begin{array}{l}\Delta \mathrm{G}_{\text {thermo }} \\
\mathrm{kcal} / \mathrm{mol}\end{array}$ & Experimental SARS-CoV-2 data \\
\hline 72 & DB12562 & Setipiprant & -22.32 & -25.92 & $\ldots$ \\
\hline 73 & DB06212 & Tolvaptan & -22.29 & -25.47 & $\ldots$ \\
\hline 74 & DB13042 & Fenoverine & -22.10 & -23.44 & $\ldots$ \\
\hline 75 & DB06630 & Anacetrapib & -21.98 & -23.47 & $\ldots$ \\
\hline 76 & DB13814 & Talampicillin & -21.64 & -20.10 & $\ldots$ \\
\hline 77 & DB11904 & Flumatinib & -21.25 & -19.23 & $\ldots$ \\
\hline 78 & DB12492 & Piritramide & -21.23 & -18.53 & $\ldots$ \\
\hline 79 & DB13050 & Tirilazad & -21.21 & -25.31 & $\ldots$ \\
\hline 80 & DB11851 & Bafetinib & -20.78 & -22.35 & $\begin{array}{l}\text { SARS-CoV-2 inhibition in A549 cells over-expressing ACE2, EC }{ }_{50} 2.2 \mu \mathrm{M} \cdot{ }^{26} \mathrm{SARS}-\mathrm{CoV}-2 \\
\text { inhibition in SARS-CoV-2 titres in A549-ACE2 cells, } \mathrm{IC}_{50}=790 \mathrm{nM}^{27}\end{array}$ \\
\hline 81 & DB12121 & Entospletinib & -20.54 & -19.41 & $\ldots$ \\
\hline 82 & DB12414 & Usistapide & -20.45 & -19.74 & $\ldots$ \\
\hline 83 & DB14878 & Liafensine & -20.23 & -24.56 & $\ldots$ \\
\hline 84 & DB12154 & Itacitinib & -19.74 & -22.45 & $\ldots$ \\
\hline 85 & DB15444 & Elexacaftor & -19.32 & -23.22 & $\ldots$ \\
\hline 86 & DB15006 & Flufenoxuron & -19.30 & -23.12 & $\ldots$ \\
\hline 87 & DB12465 & Ketanserin & -18.45 & -20.98 & $\ldots$ \\
\hline
\end{tabular}


Table S2. Molecular interactions between 20 top scoring drugs and the helicase active site

\begin{tabular}{|c|c|c|}
\hline Drug & Helicase active site interacting residues & Hydrogen bonding residues - distance $\AA$ \\
\hline 6XEZ(ADP) & Gly285, Thr286, Gly287, Lys288, His290, Arg443, Glu540 & $\begin{array}{l}\text { Thr286(N-O2B)- } 2.62 \\
\text { Thr286(OG1-O2B) - } 2.92\end{array}$ \\
\hline Aminoquinuride & $\begin{array}{l}\text { Gly282, Pro283, Pro284, Gly285, Thr286, Lys288, His290, Asp401, Gln404, Arg443, Gln537, Gly538, } \\
\text { Arg567 }\end{array}$ & $\begin{array}{l}\text { Gly282(O-N)- } 2.56 \\
\text { Gly285(O-N)-2.96 } \\
\text { Thr286(O-N)- } 3.08 \\
\text { Ser289(OG-N8)-3.05 }\end{array}$ \\
\hline Antrafenine & $\begin{array}{l}\text { Lys288, Ser289, Asp315, Ala316, Glu319, Lys320, Asp374, Glu375, Gln404, Gly538, Ser539, Glu540, } \\
\text { Tyr541, Arg567, Lys569, }\end{array}$ & Lys569(NZ-O1)- 3.34 \\
\hline Aprepitant & Thr286, Gly287, His290, Leu317, Lys320, Glu375, Arg443, Lys465, Gly538, Lys569 & Lys465(NZ-O3)-3.22 \\
\hline Astemizole & $\begin{array}{l}\text { Pro284, Thr286, Lys288, Ser289, His290, Ile293, Lys320, Glu375, Gln404, Arg443, Gln537, Glu540, } \\
\text { Asn562, Thr566, Arg567, Lys569 }\end{array}$ & $\begin{array}{l}\text { Glu540(OE1-N3)-3.09 } \\
\text { Arg567(NH1-O)-3.0 }\end{array}$ \\
\hline Bictegravir & Gly285, Ser289, His290, Leu317, Lys320, Glu375, Gln404, Arg442, Arg443, Gly538, Glu540, Arg567 & $\begin{array}{l}\text { Gly285(N-O4)-3.33 } \\
\text { Ser289(OG-O3)-3.29 }\end{array}$ \\
\hline Cabotegravir & $\begin{array}{l}\text { Gly285, Thr286, Ser289, His290, Leu317, Glu375, Gln404, Thr440, Arg442, Arg443, Gln537, Gly538, } \\
\text { Glu540 }\end{array}$ & Ser289(OG-03)-3.24 \\
\hline
\end{tabular}




\begin{tabular}{|c|c|c|}
\hline Conivaptan & $\begin{array}{l}\text { Pro284, Lys288, Ser289, Asp315, Ala316, Leu317, Lys320, Asp374, Glu375, Ile399, Asp401, Gln404, } \\
\text { Gly538, Ser539, Gly540, Tyr541, Arg567, Lys569, }\end{array}$ & $\begin{array}{l}\text { Ser289(OG-O1) -2.58 } \\
\text { Lys320(NZ-O2) - } 2.91 \\
\text { GIn404(NE2-N3) - } 2.82\end{array}$ \\
\hline Dicoumarol & $\begin{array}{l}\text { Pro284, Gly285, Thr286, Gly287, Lys288, Ser289, Lys320, Tyr324, Gln404, Gln537, Gly538, Val563, } \\
\text { Arg567 }\end{array}$ & $\begin{array}{l}\text { Thr286(O6-N) - 3.23 } \\
\text { Thr286(O6-OG1) - } 2.92\end{array}$ \\
\hline Doramapimod & $\begin{array}{l}\text { Gly282, Pro283, Pro284, Gly285, Thr286, Lys288, Ser289, Leu317, Asp374, Glu375, Asp401, Gln404, } \\
\text { Gln537, Gly538, Asn562, Val563, Arg567, }\end{array}$ & Asp374(OD1-N4) - 2.63 \\
\hline Epirubicin & $\begin{array}{l}\text { Gly282, Pro283, Pro284, Gly285, Thr286, Lys288, Ser289, His290, Ala313, Leu317, Asp374, Glu375, } \\
\text { Asp401, Gln404, Arg442, Arg443, Gln537, Gly538, Thr566, Arg567 }\end{array}$ & $\operatorname{Arg} 567(\mathrm{NH} 2-\mathrm{O})-2.69$ \\
\hline Fluspirelene & $\begin{array}{l}\text { Gly282, Pro284, Gly285, Thr286, Gly287, Lys288, Ser289, Ala316, Lys320, Asp374, Glu375, Ile399, } \\
\text { Gly400, Asp401, Gln404, Gly538, Ser539, Glu540, Asn562, Thr566, Arg567, }\end{array}$ & Asn562(ND2-F1) - 2.63 \\
\hline Hesperidin & Gly285Ala312, Asp315, Ala316, Glu319, Lys320, Gln531, Gly538, Ser539, Glu540 Tyr541 & $\begin{array}{l}\text { Ser539(OG-07) - } 3.20 \\
\text { Tyr541(OH-O13) - } 3.21\end{array}$ \\
\hline Manidipine & $\begin{array}{l}\text { Gly282, Pro284, Gly285, Thr286, Lys288, His290, Lys320, Tyr324, Asp374, Glu375, Ile399, Gly400, } \\
\text { Asp401, Gln404, Arg443, Gln537, Gly538, Glu540, Asn562, Val563, Arg567 }\end{array}$ & $\begin{array}{l}\text { Tyr324(OH-N1) - } 2.89 \\
\text { Arg442(N-O4) - } 3.11\end{array}$ \\
\hline Pimozide & $\begin{array}{l}\text { Gly282, Pro283, Pro284, Gly285, Thr286, Gly287, Lys288, Ser289, His290, Tyr324, Asp401, Gln404, } \\
\text { Arg442, Arg443, Gly538, Asn562, Thr566 Arg567, }\end{array}$ & Gly282(O-N3) -2.58 \\
\hline Rutin & $\begin{array}{l}\text { Gly282, Pro283, Pro284, Gly285, Thr286, Gly287, Lys288, Ser289, His290, Ile293, Leu317, Lys320, } \\
\text { Tyr324, Glu375, Gly400, Asp401, Gln404, Thr440, Arg442, Arg443, Gly538, Arg567 }\end{array}$ & $\begin{array}{l}\text { Gly285(N-O) }-2.94 \\
\text { Ser289(O15-O) - } 3.09\end{array}$ \\
\hline
\end{tabular}




\begin{tabular}{|c|c|c|}
\hline & & 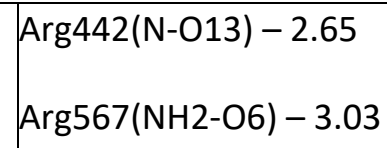 \\
\hline Sertindole & $\begin{array}{l}\text { Pro284, Lys288, Ser289, His290, Ile293, Lys320, Tyr324, Asp374, Glu375, Gln404, Gln537, Gly538, } \\
\text { Asn562, Val563, Arg567, }\end{array}$ & Asn562(ND2-F) -2.76 \\
\hline Tipranavir & $\begin{array}{l}\text { Gly282, Thr286, Gly287, Lys288, Ser289, His290, Ile293, Lys320, Tyr324, Gly538, Ser539, Glu540, } \\
\text { Arg443, Lys569 }\end{array}$ & $\begin{array}{l}\text { Tyr324(OH-O3) - 3.05 } \\
\text { Gly538(N1-O) - 3.14 }\end{array}$ \\
\hline Fexofenadine & Gly285, Thr286, Lys288, Ser289, Lys320, Tyr324, Arg442, Arg443, Lys465, Glu540 & \\
\hline Doultegravir & $\begin{array}{l}\text { Gly285, Thr286, Gly287, Ser289, His290, Leu317, Glu375, Gln404, Thr440, Arg442, Arg443, Gly538, } \\
\text { Glu540, Arg567 }\end{array}$ & $\begin{array}{l}\text { Ser289(O3-OG)- } 3.08 \\
\text { Arg442(N-F1) - 3.19 } \\
\text { Arg443(N-F1) - 3.17 }\end{array}$ \\
\hline RSV-604 & $\begin{array}{l}\text { Gly282, Pro283, Pro284, Gly285, Lys288, Ser289, Leu317, Tyr324, Asp374, Glu375, Gln404, Gln537, } \\
\text { Gly538, Arg567 }\end{array}$ & \\
\hline
\end{tabular}




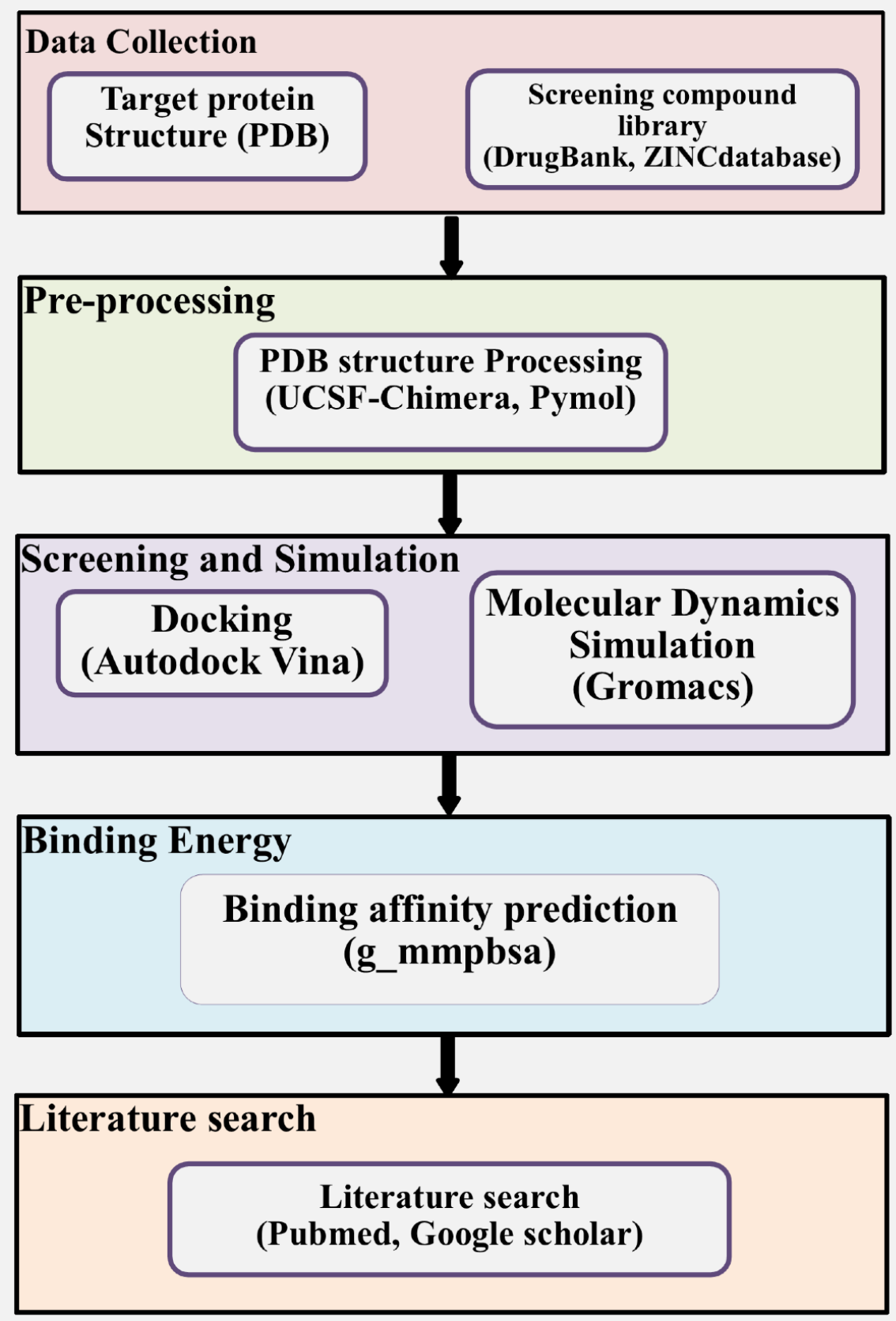


Figure S2. Superimposition of four top-scoring repurposed drugs in the helicase active site.

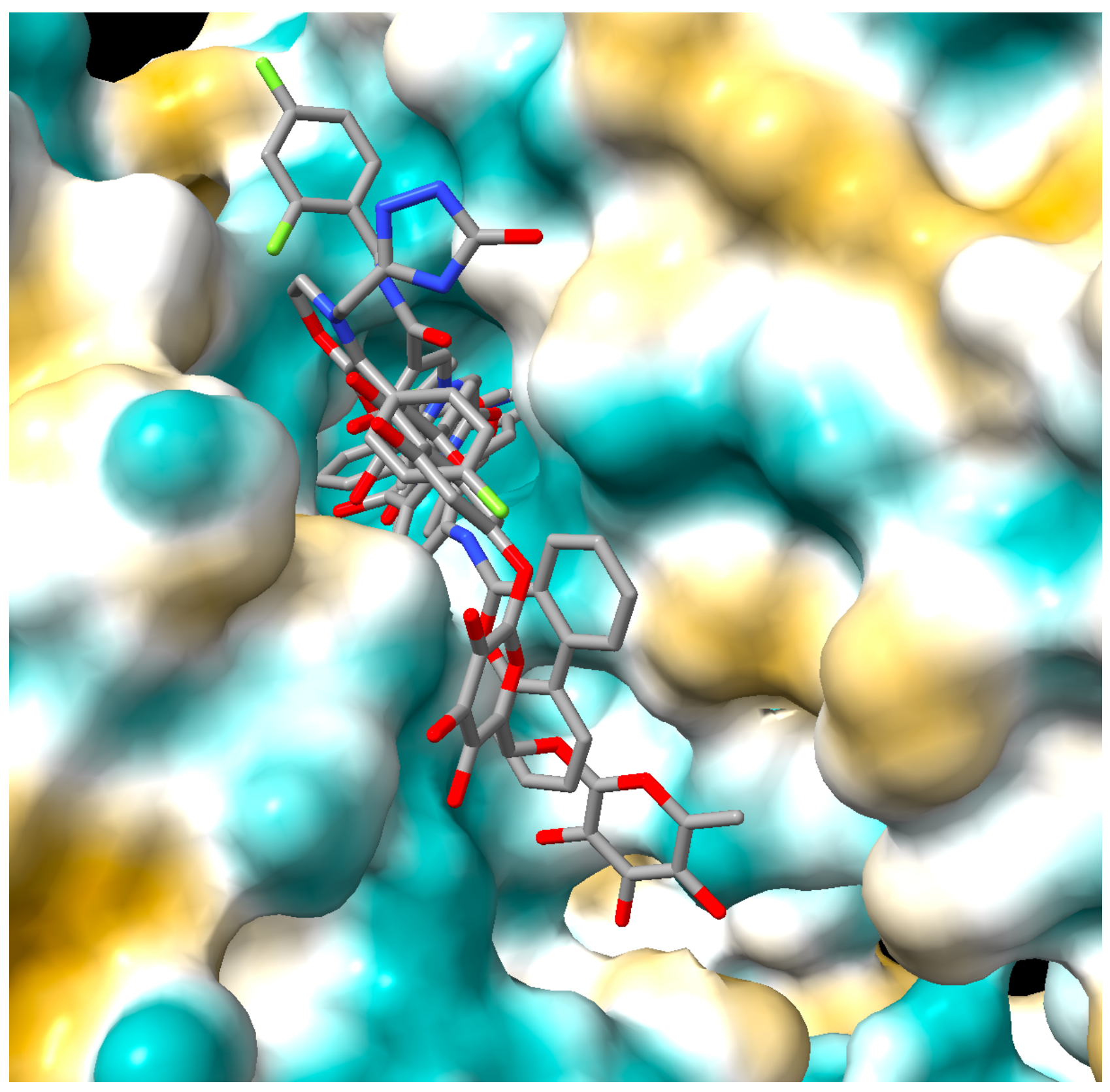


Scripts Used:

\section{1)Conf.txt}

receptor $=6 \mathrm{Y} 2 \mathrm{~F} . \mathrm{pdbqt}$

center_x $=9.245$

center_y $=-0.788$

center_z $=18.371$

size_x $=50$

size_y $=50$

size_z $=50$

num_modes $=10$

exhaustiveness $=50$

2)vina_screen.sh

\#! /bin/bash

for $f$ in CHEMBL*.pdbqt; do

$b=$ 'basename $\$$ f .pdbqt'

echo Processing ligand \$b

mkdir - $p \$ b$

vina --config conf.txt --cpu 50 --ligand \$f --out $\$[b] /$ out.pdbqt --log $\$[b] / \log . t x t$ 
done

\section{3)Script1.py}

\#! /usr/bin/env python

import sys

import glob

$\operatorname{def} \operatorname{doit}(n)$ :

file_names $=$ glob.glob('*/*.pdbqt')

everything $=[]$

failures $=[]$

print 'Found', len(file_names), 'pdbqt files'

for file_name in file_names:

file = open(file_name)

lines $=$ file.readlines ()

file.close()

try:

line $=\operatorname{lines}[1]$

result $=$ float(line.split(':')[1].split()[0])

everything.append([result, file_name])

except: 
failures.append(file_name)

everything.sort(lambda $x, y: c m p(x[0], y[0]))$

part = everything[:n]

for $p$ in part:

print $p[1]$

print

if len(failures) > 0:

print 'WARNING:', len(failures), 'pdbqt files could not be processed'

if __name__ == '_ main__:

doit(int(sys.argv[1])) 


\section{References}

1. F. Touret, M. Gilles, K. Barral, A. Nougairède, E. Decroly, X. de Lamballerie and B. Coutard, bioRxiv, 2020, DOI: 10.1101/2020.04.03.023846, 2020.2004.2003.023846.

2. P. Bellavite and A. Donzelli, Antioxid., 2020, 9, 742.

3. X. Xiao, C. Wang, D. Chang, Y. Wang, X. Dong, T. Jiao, Z. Zhao, L. Ren, C. S. Dela Cruz, L. Sharma, X. Lei and J. Wang, bioRxiv, 2020, DOI: 10.1101/2020.07.06.188953, 2020.2007.2006.188953.

4. X. Xie, A. E. Muruato, X. Zhang, K. G. Lokugamage, C. R. Fontes-Garfias, J. Zou, J. Liu, P. Ren, M. Balakrishnan, T. Cihlar, C.-T. K. Tseng, S. Makino, V. D. Menachery, J. P. Bilello and P.-Y. Shi, bioRxiv, 2020, 2020.06.22.165712.

5. C. J. Kuo, T. L. Chao, H. C. Kao, Y. M. Tsai, Y. K. Liu, L. H. Wang, M. C. Hsieh, S. Y. Chang and P. H. Liang, Antimicrob. Agents Chemother., 2021, DOI: 10.1128/AAC.02577-20.

6. A. Pickard, B. C. Calverley, J. Chang, R. Garva, Y. Lu and K. E. Kadler, bioRxiv, 2021, 2021.01.31.428851.

7. N. Yamamoto, S. Matsuyama, T. Hoshino and N. Yamamoto, bioRxiv, 2020, DOI: 10.1101/2020.04.06.026476, 2020.2004.2006.026476.

8. E. C. Vatansever, K. S. Yang, A. K. Drelich, K. C. Kratch, C.-C. Cho, K. R. Kempaiah, J. C. Hsu, D. M. Mellott, S. Xu, C.-T. K. Tseng and W. R. Liu, Proc. Natl. Acad. Sci. USA, 2021, 118, e2012201118.

9. B. Rizzuti, F. Grande, F. Conforti, A. Jimenez-Alesanco, L. Ceballos-Laita, D. Ortega-Alarcon, S. Vega, H. T. Reyburn, O. Abian and A. Velazquez-Campoy, Biomed., 2021, 9, 375.

10. S. Weston, C. M. Coleman, R. Haupt, J. Logue, K. Matthews and M. B. Frieman, bioRxiv, 2020, DOI: 10.1101/2020.03.25.008482, 2020.2003.2025.008482.

11. J. Dyall, C. M. Coleman, B. J. Hart, T. Venkataraman, M. R. Holbrook, J. Kindrachuk, R. F. Johnson, G. G. Olinger, P. B. Jahrling, M. Laidlaw, L. M. Johansen, C. M. Lear-Rooney, P. J. Glass, L. E. Hensley and M. B. Frieman, Antimicrob. Agents Chemother., 2014, 58, 4885-4893.

12. M. H. Raymonda, J. H. Ciesla, M. Monaghan, J. Leach, G. Asantewaa, L. A. Smorodintsev-Schiller, M. M. Lutz, X. L. Schafer, T. Takimoto, S. Dewhurst, J. Munger and I. S. Harris, bioRxiv, 2020, DOI: 10.1101/2020.11.25.398859, 2020.2011.2025.398859.

13. L. Riva, S. Yuan, X. Yin, L. Martin-Sancho, N. Matsunaga, S. Burgstaller-Muehlbacher, L. Pache, P. P. De Jesus, M. V. Hull, M. Chang, J. F. Chan, J. Cao, V. K. Poon, K. Herbert, T. T. Nguyen, Y. Pu, C. Nguyen, A. Rubanov, L. Martinez-Sobrido, W. C. Liu, L. Miorin, K. M. White, J. R. Johnson, C. Benner, R. Sun, P. G. Schultz, A. Su, A. Garcia-Sastre, A. K. Chatterjee, K. Y. Yuen and S. K. Chanda, bioRxiv, 2020, DOI: 10.1101/2020.04.16.044016.

14. S. Malik, A. Gupta, X. Zhong, T. P. Rasmussen, J. E. Manautou and R. Bahal, Pharmaceut., 2020, 13, 188.

15. K. B. Ku, H. J. Shin, H. S. Kim, B.-T. Kim, S.-J. Kim and C. Kim, J. Microbiol. Biotechnol., 2020, 30, 1843-1853. 
16. J. S. Shin, E. Jung, Y. Jang, S. B. Han and M. Kim, ChemRxiv, 2020, chemrxiv.12496547.v1

17. G. Garcia Jr, A. Sharma, A. Ramaiah, C. Sen, D. B. Kohn, B. N. Gomperts, C. N. Svendsen, R. Damoiseaux and V. Arumugaswami, Cell Rep., 2020, DOI: 10.2139/ssrn.3682004, in press.

18. J.-T. Jan, T.-J. R. Cheng, Y.-P. Juang, H.-H. Ma, Y.-T. Wu, W.-B. Yang, C.-W. Cheng, X. Chen, T.-H. Chou, J.-J. Shie, W.-C. Cheng, R.-J. Chein, S.-S. Mao, P.-H. Liang, C. Ma, S.-C. Hung and C.-H. Wong, Proc. Natl. Acad. Sci. USA, 2021, 118, e2021579118.

19. R. Killick, C. Ballard, P. Doherty and G. Williams, ChemRxiv, 2020, chemrxiv.12327554.v1

20. R. Choi, M. Zhou, R. Shek, J. W. Wilson, L. Tillery, J. K. Craig, I. A. Salukhe, S. E. Hickson, N. Kumar, R. M. James, G. W. Buchko, R. Wu, S. Huff, T.-T. Nguyen, B. L. Hurst, S. Cherry, L. K. Barrett, J. L. Hyde and W. C. Van Voorhis, bioRxiv, 2021, DOI: 10.1101/2021.01.21.427657, 2021.2001.2021.427657.

21. N. Mulgaonkar, H. Wang, S. Mallawarachchi, S. Fernando, B. Martina and D. Ruzek, bioRxiv, 2020, DOI: 10.1101/2020.06.18.158196, 2020.2006.2018.158196.

22. F. Touret, J.-S. Driouich, M. Cochin, P. Rémi Petit, M. Gilles, K. Barthélémy, G. Moureau, D. Malvy, C. Solas, X. de Lamballerie and A. Nougairède, bioRxiv, 2020, DOI: 10.1101/2020.11.17.386904, 2020.2011.2017.386904.

23. Y. Han, L. Yang, X. Duan, F. Duan, B. E. Nilsson-Payant, T. M. Yaron, P. Wang, X. Tang, T. Zhang, Z. Zhao, Y. Bram, D. Redmond, S. Houghton, D. Nguyen, D. Xu, X. Wang, S. Uhl, Y. Huang, J. L. Johnson, J. Xiang, H. Wang, F. C. Pan, L. C. Cantley, B. R. tenOever, D. D. Ho, T. Evans, R. E. Schwartz, H. J. Chen and S. Chen, bioRxiv, 2020, DOI: 10.1101/2020.05.05.079095, 2020.2005.2005.079095.

24. M. Milani, M. Donalisio, R. M. Bonotto, E. Schneider, I. Arduino, F. Boni, D. Lembo, A. Marcello and E. Mastrangelo, Antiviral Res., 2021, 189, 105055.

25. B. Ellinger, D. Bojkova, A. Zaliani, J. Cinatl, C. Claussen, S. Westhaus, J. Reinshagen, M. Kuzikov, M. Wolf, G. Geisslinger, P. Gribbon and S. Ciesek, Res. Square, 2021, s-23951/v1.

26. N. Drayman, K. A. Jones, S.-A. Azizi, H. M. Froggatt, K. Tan, N. I. Maltseva, S. Chen, V. Nicolaescu, S. Dvorkin, K. Furlong, R. S. Kathayat, M. R. Firpo, V. Mastrodomenico, E. A. Bruce, M. M. Schmidt, R. Jedrzejczak, M. Á. Muñoz-Alía, B. Schuster, V. Nair, J. W. Botten, C. B. Brooke, S. C. Baker, B. C. Mounce, N. S. Heaton, B. C. Dickinson, A. Jaochimiak, G. Randall and S. Tay, bioRxiv, 2020, DOI: 10.1101/2020.08.31.274639, 2020.2008.2031.274639.

27. B. Meyer, J. Chiaravalli, S. Gellenoncourt, P. Brownridge, D. P. Bryne, L. A. Daly, M. Walter, F. Agou, L. A. Chakrabarti, C. S. Craik, C. E. Eyers, P. A. Eyers, Y. Gambin, E. Sierecki, E. Verdin, M. Vignuzzi and E. Emmott, bioRxiv, 2021, DOI: 10.1101/2020.09.16.297945, 2020.2009.2016.297945. 